\title{
Unusual mantle Poisson's ratio, subduction, and crustal structure in central Alaska
}

\author{
Giovannibattista Rossi, ${ }^{1}$ Geoffrey A. Abers, ${ }^{1}$ Stephane Rondenay, ${ }^{2}$ \\ and Douglas H. Christensen ${ }^{3}$ \\ Received 22 July 2005; revised 14 April 2005; accepted 2 June 2006; published 22 September 2006.
}

[1] Subduction zones alter the upper plate in a variety of ways, including metasomatism via slab-derived fluids and accretion of exotic terranes. These processes should produce distinctive seismic signatures, as seismic velocities are sensitive to compositional variations. A new method is developed to estimates depths to interfaces and Poisson's ratio $(V p / V s$ ratio) for dipping layered structures, by stacking teleseismic receiver functions. It also estimates crustal $\mathrm{Vp} / \mathrm{Vs}$ and thickness. Using this method, we analyze a broadband data set from the central Alaska subduction zone, to seek evidence for mantle wedge composition. Crustal thickness varies from 27 to $45 \mathrm{~km}$, and crustal $V p / V s$ indicates an intermediate to mafic composition, expected for these accreted island arc terranes. Inversions for mantle structure confirm the presence of a $15-20 \mathrm{~km}$ thick low-velocity zone atop of the downgoing plate to $130 \mathrm{~km}$ depth, perhaps subducted crust of an exotic terrane. $V p / V s$ in the mantle wedge allows for $15 \pm 15 \%$ serpentinization where the slab is $<80 \mathrm{~km}$ deep and the wedge is cold. Where the slab is deeper, $V p / V s$ for the mantle wedge is unusually low, $<1.7$. This value is lower than predicted for any common mantle mineral and may indicate significant quantities of quartz, provided that past physical properties measurements are not grossly in error. These results suggest that the mantle wedge in subduction zones can occasionally differ substantially in bulk composition from normal subcrustal mantle, perhaps because collisions of exotic terranes cause tectonic mixing of crustal material into the mantle.

Citation: Rossi, G., G. A. Abers, S. Rondenay, and D. H. Christensen (2006), Unusual mantle Poisson's ratio, subduction, and crustal structure in central Alaska, J. Geophys. Res., 111, B09311, doi:10.1029/2005JB003956.

\section{Introduction}

[2] The Earth's upper mantle appears to be dominantly peridotite, as revealed by xenoliths, seismic velocities, and chemistry of magmas [e.g., Green and Falloon, 1998]. During subduction and collision this average composition may be significantly modified by at least three processes. First, subduction of oceanic sediment, crust and underlying mantle releases abundant fluids, that can hydrate much of the upper mantle [e.g., Schmidt and Poli, 1998], forming hydrous minerals such as serpentine, chlorite, brucite and talc in the forearc where temperatures are sufficiently cold [e.g., Hyndman and Peacock, 2003]. Besides the addition of $\mathrm{H}_{2} \mathrm{O}$, this flux of brines may add significant silica to peridotites [Bebout, 1996]. Second, subduction during collision may transport substantial volumes of material formed at the Earth's surface to mantle depths, including fragments

\footnotetext{
${ }^{1}$ Department of Earth Sciences, Boston University, Boston, Massachusetts, USA.

${ }^{2}$ Department of Earth, Atmospheric and Planetary Sciences, Massachusetts Institute of Technology, Cambridge, Massachusetts, USA.

${ }^{3}$ Geophysical Institute, University of Alaska, Fairbanks, Fairbanks, Alaska, USA.

Copyright 2006 by the American Geophysical Union. 0148-0227/06/2005JB003956\$09.00
}

of continental crust, metasediments, and remanent island arcs. Thick columns of crust may be too buoyant to subduct [Molnar and Gray, 1979], but the discovery of ultrahighpressure terranes at several localities around the world [Ernst and Liou, 1999] shows that crustal rocks do, occasionally, experience upper mantle pressures and temperatures. Third, where temperatures are sufficiently high, partial melting results in chemical depletion of the residual mantle. All three of these processes alter bulk composition, so are potentially observable by seismic imaging.

[3] Here, we develop and apply a new technique to constrain physical properties of the mantle wedge in Alaska, making use of a dense new data set from the Broadband Experiment Across the Alaska Range (BEAAR). The main goal is to measure the mantle Poisson's ratio, which is sensitive to some variations in composition. We also obtain constraints on interface depths within the subducting plate, and as a byproduct, crustal structure. Poisson's ratio is a monotonic function of the ratio of $P$ velocity $(V p)$ to $S$ velocity $(V S)$, and has been shown to be $0.24-0.28(V p / V S=$ 1.71-1.81) for all but a handful of common rocks and rockforming minerals [Brocher, 2005; Christensen, 1996]. The main exceptions are serpentine, which has Poisson's ratio exceeding $0.35(V p / V s>2.1)$, and quartz, which has Poisson's ratio near 0.1 at crustal pressures $(V p / V s=1.5)$. 

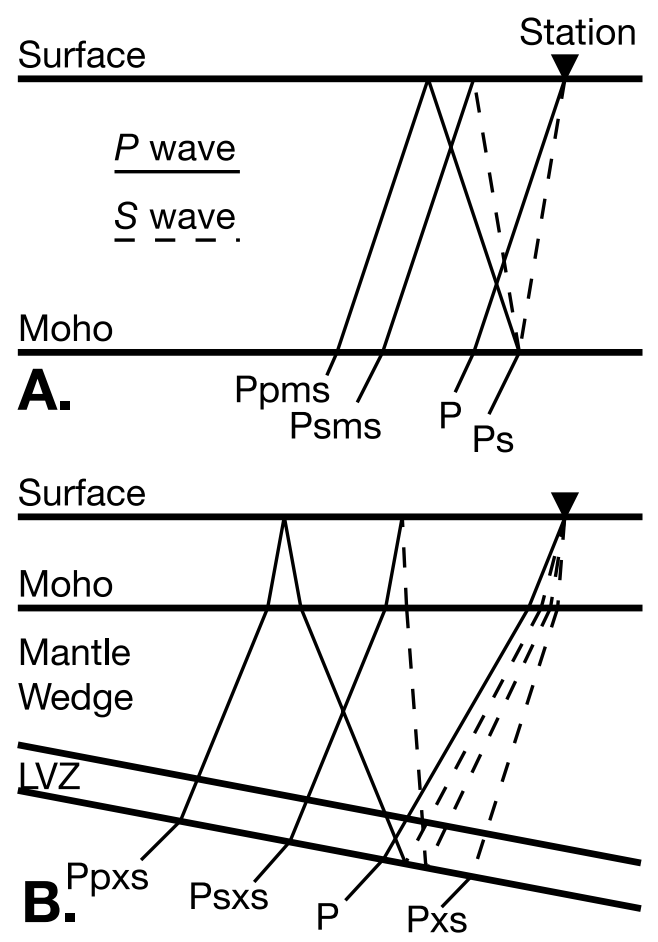

Figure 1. Ray geometry and nomenclature for teleseismic $P$-to- $S$ converted waves. (a) Conversions at upper plate Moho. The " $m$ " denotes conversion or reflection at interface. (b) Conversions at Moho of dipping, subducting plate. The " $x$ " denotes conversion or reflection at interface following common usage for slab interaction phases [e.g., Matsuzawa et al., 1986].

Poroelastic effects can also change Poisson's ratio in a variety of ways and, for most realistic pore geometries, act to increase $V p / V s$ as melt or fluid content increase [Takei, 2002].

[4] Teleseismic converted phases can be used to measure $V p / V s$ and thickness of continental crust [Zandt and Ammon, 1995], by comparing the delay times between the arrivals of the direct $P$ wave, the $P$-to- $S$ conversion off the Moho (PS), and one or more multiples (Figure 1). One simplification in published methods is the implicit assumption of flat-lying interfaces, clearly violated for reverberations within the mantle wedge of most subduction zones. To remedy this problem, we extend a common stacking approach [Chevrot and van der Hilst, 2000; Zhu and Kanamori, 2000] to dipping interfaces. The inversion is applied to the mantle wedge to measure its thickness and vertically averaged $V p / V s$. One goal of this study is to test the hypothesis that forearcs undergo extensive serpentinization [e.g., Hyndman and Peacock, 2003], by searching for the anomalously elevated $V p / V s$. Where the plate is shallow and wedge temperatures inferred to be low, we observe slightly elevated $V p / V s$ consistent with the presence of $15 \pm$ $15 \%$ serpentinization. Where the slab is $>80 \mathrm{~km}$ deep low $V p / V s$ is less than 1.7 , an observation difficult to reconcile with a conventional peridotitic mantle. Possibly, the subduction of large crustal fragments has significantly increased the silica content of parts of the mantle wedge.

\section{Tectonic Setting}

[5] The Pacific plate subducts underneath the Alaskan margin of the North American plate. Above the subduction zone elevated topography forms in the Alaska Range in central Alaska and the other ranges near the coast [Plafker et al., 1994], but arc volcanism is virtually absent over the easternmost $350 \mathrm{~km}$ of subduction. Wadati-Benioff zone (WBZ) seismicity extends to $120-150 \mathrm{~km}$ depth and terminates eastward at $148^{\circ} \mathrm{W}$ (Figure 2). At depths less than $50 \mathrm{~km}$ the descending plate dips unusually shallowly, $<5^{\circ}$ [Page et al., 1989], steepening to $25^{\circ}$ at greater depth [Ratchkovski and Hansen, 2002]. The top of the downgoing slab has been imaged via receiver functions as a lowvelocity layer to $130 \mathrm{~km}$ depth, with all WBZ seismicity lying inside this layer [Ferris et al., 2003]. The layer is unusually thick for subducted oceanic crust, $14-22 \mathrm{~km}$, and has been interpreted as result of the subduction of a thick colliding crustal block.

[6] The southern Alaska crust consists of a series of exotic terranes accreted since the Mesozoic, separated by major faults (Figure 2) [e.g., Saleeby, 1983]. While the accreted terranes vary widely in provenance, a first-order boundary can be drawn at the Denali-Hines Creek fault system between the accreted mafic oceanic arc terranes to the south and the para-autochthonous Yukon-Tanana terrane of continental affinity to the north. The Wrangellia, Chugach and Prince William composite terranes are dominantly magmatic rocks, oceanic plateaus, and associated metasediments [Plafker et al., 1989]. The Denali and Hines Creek fault systems may have formed originally as a subduction zone in the early Cretaceous and mark the closure of an ocean basin [Ridgway et al., 2002], but now the fault systems form an active strike-slip zone paralleling the Alaska Range [Plafker et al., 1994]. Active source

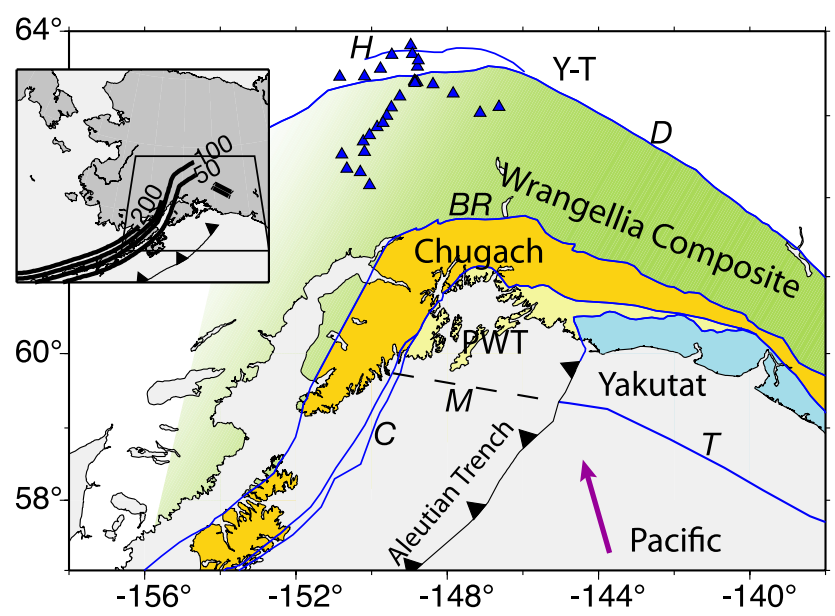

Figure 2. Southern Alaska composite terranes and bounding faults. Terrane abbreviations area PWT, Prince William Terrane; Y-T, Yukon-Tanana Terrane. Faults are BR, Border Ranges; C, Contact; D, Denali; H, Hines Creek; T, Transition. M, slope magnetic anomaly. Arrow shows direction of Pacific-North America motion, at $55 \mathrm{~mm} \mathrm{yr}^{-1}$. Triangles denote BEAAR stations. From Plafker et al. [1994] and Brocher et al. [1994]. Inset shows area of map, and contours to slab at $50 \mathrm{~km}$ intervals labeled. 


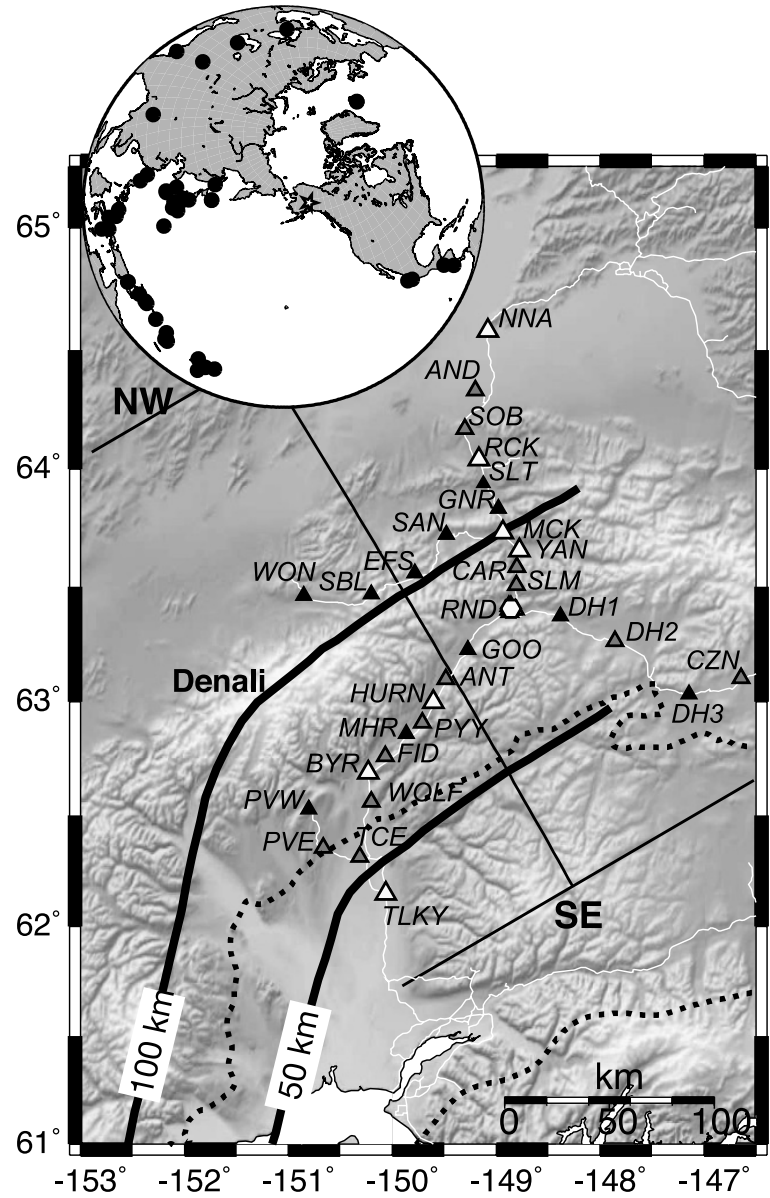

Figure 3. BEAAR array and topographic relief. Open triangles represent seismic stations operating 28 months, gray triangles are stations operating 15 months, and black triangles denote stations operating 5 months. Thick contours show Pacific plate isobaths based on seismicity. Thin line shows location of cross section for subsequent figures. Thick dotted line outlines positive magnetization anomaly [Blakely et al., 2005]. Inset shows locations of earthquakes used in this study (circles).

imaging along the TACT profile, near $146^{\circ} \mathrm{W}$, shows that the major terrane-bounding faults resemble thrusts and dip northward at low angles to at least $20-25 \mathrm{~km}$ depth [Fuis et al., 1991], although the Denali fault forms a more vertical boundary [Brocher et al., 2004].

[7] The Yakutat terrane currently impinges on southern Alaska, translating with the Pacific Plate offshore [Fletcher and Freymueller, 1999], and resulting in ongoing deformation in the Gulf of Alaska [Pavlis et al., 2004; Plafker et al., 1994]. The imaged thickness and velocity structure of this terrane offshore [Brocher et al., 1994] closely resembles that seen in receiver functions at $60-130 \mathrm{~km}$ depth, suggesting that the Yakutat terrane is subducting to great depth beneath Central Alaska [Ferris et al., 2003].

[8] In the mantle wedge above the subducting plate, $P$ wave tomography shows velocities $3-6 \%$ slower than surroundings [Eberhart-Phillips et al., 2003; Zhao et al., 1995], as does $P n$ and $S n$ inversion [McNamara and Pasyanos, 2002]. Seismic attenuation in the wedge is low (high $Q$ ) where the subducting plate where the plate is
$<80 \mathrm{~km}$ deep, with an abrupt change to high attenuation above where the plate passes below $80 \mathrm{~km}$ depth, indicating a large northward increase in wedge temperature [Stachnik et al., 2004]. Thus the wedge can be divided into a northern, hot and flowing region, and a southern, cold region probably isolated from wedge flow [Abers et al., 2006].

\section{Data and Method}

[9] Layer depths and $V p / V s$ are measured from the modeconverted signals in the coda of teleseismic $P$ waves. The procedure to estimate these parameters is as follows. (1) A source pulse is deconvolved from teleseismic $P$ records for each earthquake, to generate an estimate of the scattered radial and tangential component wavefield [Rondenay et al., 2005]. (2) Records are collected for each station. (3) For the crust, the deconvolved signals are stacked after applying moveout corrections for each major Moho conversion (Pms, Ppms, Psms; Figure 1), assuming $V p$, for a range of $V p / V s$. (4) By finding the arrival producing the most coherent stack over all conversions, the Moho depth and crustal $V p / V s$ are estimated along with uncertainties [e.g., Chevrot and van der Hilst, 2000; Zhu and Kanamori, 2000]. (5) Using the derived crustal structure as a constraint, step (3) is repeated for mode conversions from the interface at the top of the downgoing plate. Because of strong ray bending effects, the moveout corrections must be calculated by taking layer dip into account, assuming an initial model of slab geometry. (6) Step (4) is repeated for the conversions from the top of the slab, giving depth to slab, $V p / V s$ of the mantle wedge, and thickness of a low-velocity zone (LVZ) found at the top of the slab. These steps are described in detail below.

\subsection{Data}

[10] The BEAAR PASSCAL experiment consisted of 36 broadband seismographs deployed across central Alaska from June 1999 to August 2001 (Figure 3). Seismometers were located above the subducting Pacific plate where the WBZ descends from 50 to $>150 \mathrm{~km}$ depth, mostly along a dense transect following the road system. Seismographs were deployed from four to 25 months and recorded at 50 samples per second, on CMG-3T and CMG-3ESP broadband sensors giving flat velocity response to 120 and $30 \mathrm{~s}$ periods, respectively. GPS clocks corrected the times to within $1 \mathrm{~ms}$.

\subsection{Data Processing}

[11] The primary signal used here are scattered $S V$ and $S H$ wavefields in the coda of teleseismic $P$ waves, as in traditional receiver function analyses. For this study, we select events with body wave magnitudes $>6$ and signal-tonoise ratios $>2$ following deconvolution. These 46 events illuminate the study area from a variety of back azimuths (Figure 3, inset). Because individual vertical components can be noisy, a multichannel approach is used to estimate the incident $P$ wave of each selected event recorded by the array [Bostock and Rondenay, 1999]. The estimated incident waveform thus obtained is less affected by site-specific noise and produces stable deconvolution to higher frequencies than traditional receiver functions.

[12] All seismograms recorded for one earthquake are transformed into an upgoing wave vector $(P, S V, S H)$ using 

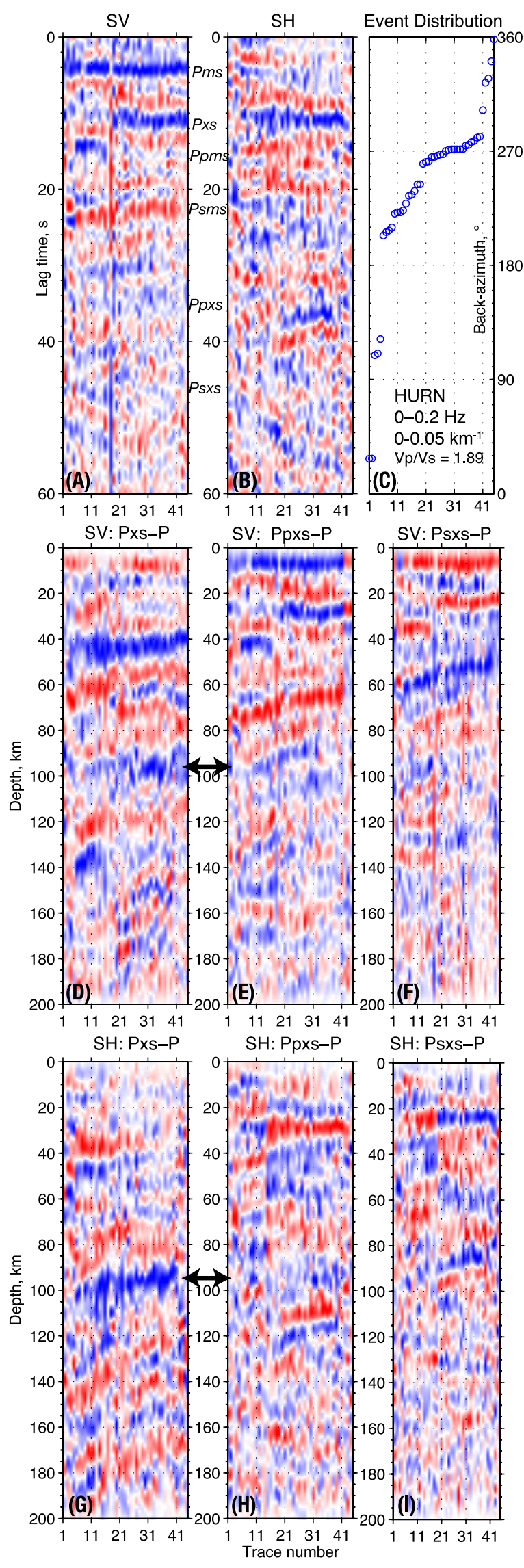

the inverse free-surface transfer matrix [Kennett, 1991], for a $90 \mathrm{~s}$ window following the onset of $P$. This procedure isolates the incident $P$ wave from the two scattered $S$ components. The $P$ components are then aligned using multichannel cross correlation [VanDecar and Crosson, 1990], and the incident wavefield is estimated by performing an eigenimage decomposition of the aligned $P$ wave section and only retaining the first one or two eigenmodes, which represent the portion of the signal that is common to all stations. The resulting incident $P$ wave is deconvolved from the individual $S V$ and $S H$ signals, producing for each station an estimate of the near-receiver scattered wavefield due to an impulsive incident wave. The collection of such scattered waves, for each station from all earthquakes, constitutes our basic data set. For full details on this method, see Rondenay et al. [2005].

[13] In the BEAAR data, both the radial and tangential receiver functions show a high-amplitude arrival 6-15 $\mathrm{s}$ after $P$ (Figures $4 \mathrm{a}$ and $4 \mathrm{~b}$ ), identified as the subducting Pacific plate by Ferris et al. [2003]. The conversion can only be generated by a LVZ with well-defined top and bottom boundaries, and the LVZ correlates with the location of the WBZ seismicity. The amplitude of the conversion varies with back azimuth, and is maximum for rays traveling up the dip of the slab. The three strongest conversions are the upgoing $P$-to- $S$ conversion, termed here $P x s$, and its free-surface multiples Ppxs and Psxs, arriving on either the $S V$ or $S H$ component (equivalent to the backscattered modes of Bostock et al. [2001]). Figure 1 illustrates the ray nomenclature; " $x$ " denotes conversions from the top of the slab as in previous studies [e.g., Matsuzawa et al., 1986]. The other major conversions observed correspond to the Moho discontinuity (Pms and its free-surface multiples, Ppms and Psms). No significant $S H$ converted energy is observed for the Moho conversion, consistent with a subhorizontal discontinuity and relatively isotropic crust.

[14] To model the observed signals, we solve for parameters of a four-layer structure (Figure 5) using the stacking method described below. We first invert the early parts of the record for crustal thickness and average crustal $V p / V s$, then fix these parameters and solve for the mantle wedge thickness and $V p / V s$, and LVZ thickness. The $\mathrm{P}$ wave velocity $(V p)$ is constrained independently from regional traveltimes, as described in section 4.2.

Figure 4. Sample data from station HURN, typical of well-sampled signals. (a) Deconvolved SV component for 46 events, sorted by back azimuth, low-pass filtered at $0.2 \mathrm{~Hz}$. Blue shows positive-amplitude arrivals; red shows negative. Major predicted phases are labeled, for a nominal ray parameter $\left(0.06 \mathrm{~s} \mathrm{~km}^{-1}\right)$, flat-lying interfaces, and provisional structure. (b) Deconvolved SH component. (c) Back azimuths to stations. (d)-(i) Results of moveout and sign correction, for SV (Figures $4 \mathrm{~d}-4 \mathrm{f}$ ) and $\mathrm{SH}$ (Figures $4 \mathrm{~g}-3 \mathrm{i}$ ). Traces are low-pass filtered below wave number of $0.05 \mathrm{~km}^{-1}$, and corrected so nominal sign of phase is positive (blue). Each trace applies moveout for a specific phase converting or reflecting off the slab Moho, as in Figure 1. Figures $4 \mathrm{~d}$ and $4 \mathrm{~g}$ are for Pxs; Figures $4 \mathrm{e}$ and 4h are for Ppxs; Figures $4 \mathrm{f}$ and $4 \mathrm{i}$ are for Psxs. Arrows show inferred slab Moho. 
Surface

\begin{tabular}{ll} 
& $V p=6.5 \mathrm{~km} / \mathrm{s}$ \\
Crust & $\mathrm{Vp} / \mathrm{Vs}=$ Estimated \\
& $\mathrm{L}=$ Estimated \\
Moho & \\
\hline
\end{tabular}

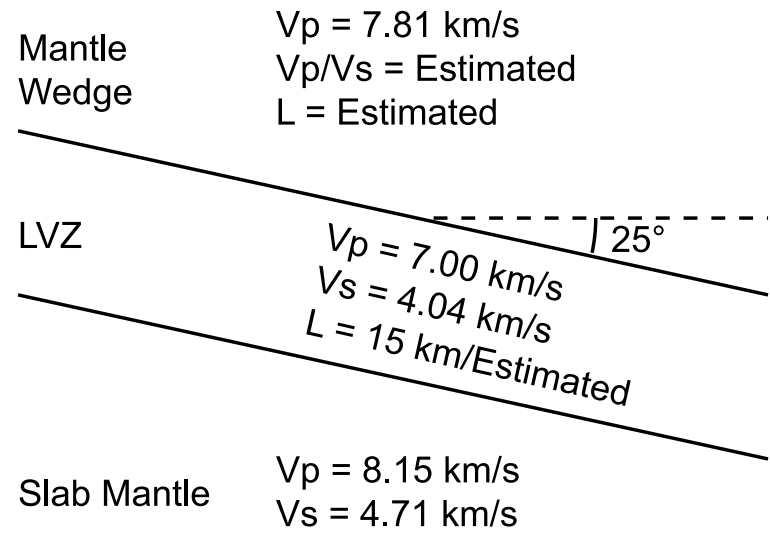

Figure 5. Velocity model used for calculating moveout corrections. Parameters listed as "estimated" are derived by inversion, and others are fixed or measured as described in text. Slab orientation assumed downdip at $330^{\circ}$ azimuth. Layer thicknesses $(\mathrm{L}, \mathrm{km})$ are measured vertically, directly beneath each station. LVZ thickness is fixed at $15 \mathrm{~km}$ in calculating moveout correction but is redetermined later as describe in text.

\subsection{Moveout Correction}

[15] For a given station, each converted phase arrives at times that vary with the incident ray parameter $p$ and, for dipping (slab) layers, the back azimuth $\phi$. To correct for this effect, we apply azimuth-dependent moveout corrections to convert time to depth separately for each event and phase Pxs, Ppxs, and Psxs. The corrections depend upon an assumed $V p$ and $V p / V s$, tested over a range of values. The moveout-corrected traces are filtered and stacked for all events and phases at one station. The stacking approach used here resembles that of previous workers [Chevrot and van der Hilst, 2000; Zhu and Kanamori, 2000], generalized to dipping layers. The $V p / V_{S}$ yielding the highest stack amplitude represents the best fitting model.

[16] The basic approach can be generalized to any structure with planar dipping layers and constant velocities between discontinuities (e.g., Figure 5). If velocities are constant immediately above a dipping discontinuity, then the traveltimes for phases converted from the discontinuity are linear with respect to changes in that discontinuity's depth [Diebold, 1987]. In other words,

$$
t_{k}=z f_{k}(p, \phi ; \mathbf{m})+\tau_{k}(p, \phi ; \mathbf{m}),
$$

where $t_{k}$ is the predicted lag time of the $k$ th phase, $f_{k}$ and $\tau_{k}$ are terms that depend upon the velocity model and incident ray, $k$ is an index describing the phase (Pxs, Ppxs, or Psxs), z is the depth to the interface as measured directly below the station, and $\mathbf{m}$ represents the velocity model (e.g., Figure 5). Both $p$ and $\phi$ are well constrained for teleseismic signals, derived here from the iasp91 traveltime tables [Kennett and
Engdahl, 1991]. Because the moveout is linear with respect to $z$, applying it requires calculating $f_{k}$ and $\tau_{k}$, for each station and phase, and then estimating the predicted depth $z_{k}$ from phase $k$ at each observed lag time $t$ :

$$
z_{k}=\left(t-\tau_{k}\right) / f_{k} .
$$

In the case of a horizontal interface, we use a simple analytical solution to calculate $f_{k}$ and $\tau_{k}$, from the layer velocities and $p$ [e.g., Zhu and Kanamori, 2000]. For a dipping interface we derive $\tau_{k}$ and $f_{k}$ numerically, using the method of Frederiksen and Bostock [2000] to calculate traveltimes and finite difference derivatives. The model used for calculating $\tau_{k}$ and $f_{k}$ in slab inversions includes the crust derived from earlier crustal inversion, and a slab LVZ as constrained by Ferris et al. [2003] (Figure 5). The resulting moveout is calculated and applied for each of a suite of trial models, varying $V p / V s$ above the interface. Predicted phase amplitudes are also calculated, and used to correct for the sign of phases before stacking.

[17] Figure 4 shows examples of the moveout-corrected slab signal at one typical station, HURN, operating for the full deployment. Figures $4 \mathrm{a}$ and $4 \mathrm{~b}$ show the receiver functions after deconvolution sorted by back azimuth; the major phases on Figure 1 can be seen although the slab arrivals show significant moveout with azimuth, as expected. Figures $4 \mathrm{~d}-4 \mathrm{i}$ show the record sections traces as a function of interface depth after moveout correction for each component and major phase (Pxs, Ppxs, Psxs). They indicate a consistent positive-polarity slab arrival at $95.5 \mathrm{~km}$ depth. Other choices of $V p / V s$ would result in differences in estimated depths for different phases.

\subsection{Inversion}

[18] After applying the time and sign corrections, moveout-corrected records for each station and assumed $\mathrm{Vp} / V_{S}$ are stacked over all events and phases, in depth intervals where conversions are expected. The term "phase" here refers to a particular combination of conversion (Pxs, Ppxs, or Psxs) and component ( $S V$ or $S H)$. The stack should have maximum amplitude at the depth corresponding to the dominant mode conversion, largest for the correct $V p / V s$. For the $j$ th velocity model $(V p / V s)$, the stacked, moveoutcorrected wave train can be written

$$
U_{j}(z)=\frac{1}{N} \sum_{i, k} w_{k} s_{i j k}(z),
$$

where $i(=1, \ldots, N)$ denotes each event, $k(=1, \ldots, 6)$ denotes each phase (e.g., Pxs, Ppxs, Psxs for $S V, S H)$, and $s_{i j k}(z)$ is a moveout-corrected trace described in section 3.3. Only the $3 \mathrm{SV}$ modes are used for Moho stacks, because $S H$ conversions are nominally zero for flat layers. Each phase is assigned a weight $w_{k}$, normalized so that $\Sigma w_{k}=1$. The $U_{j}(z)$ are searched for its maximum amplitude $\left(U_{0}\right)$ over all models $j$ and depths $z$, to determine the optimal interface depth and $V p / V s$ (Figure 6). At a nominal $V p / V s$ and $z$ corresponding to this peak amplitude, the standard deviation $\left(\sigma_{k}\right)$ of individual traces $s_{i j k}(z)$ about $U_{j}(z)$ is calculated for each phase, and the $w_{k}$ are scaled to $1 / \sigma_{k}$. This procedure downweights phases which stack less coherently, as they 


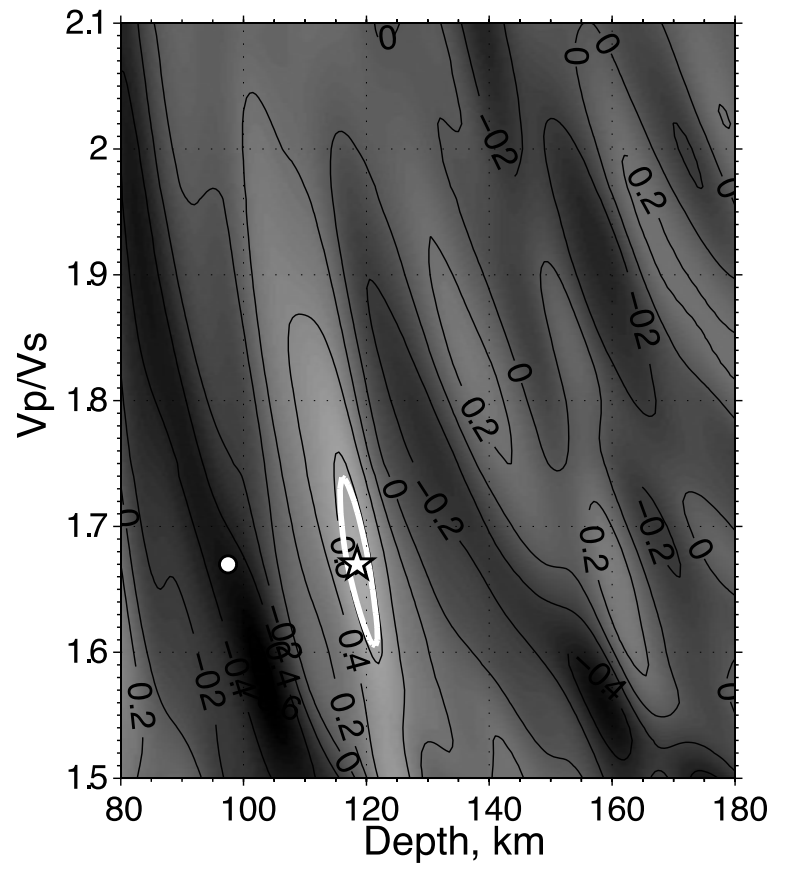

Figure 6. Stack of all modes $U_{j}(z)$ at station MCK. Individual modes and format are shown in Figure 1; $\mathrm{SH}$ Psxs is not used. Open star indicates best fitting solution bound by $85 \%$ confidence limit (white line), and open circle indicates corresponding top of the LVZ as indicated by negative amplitude peak.

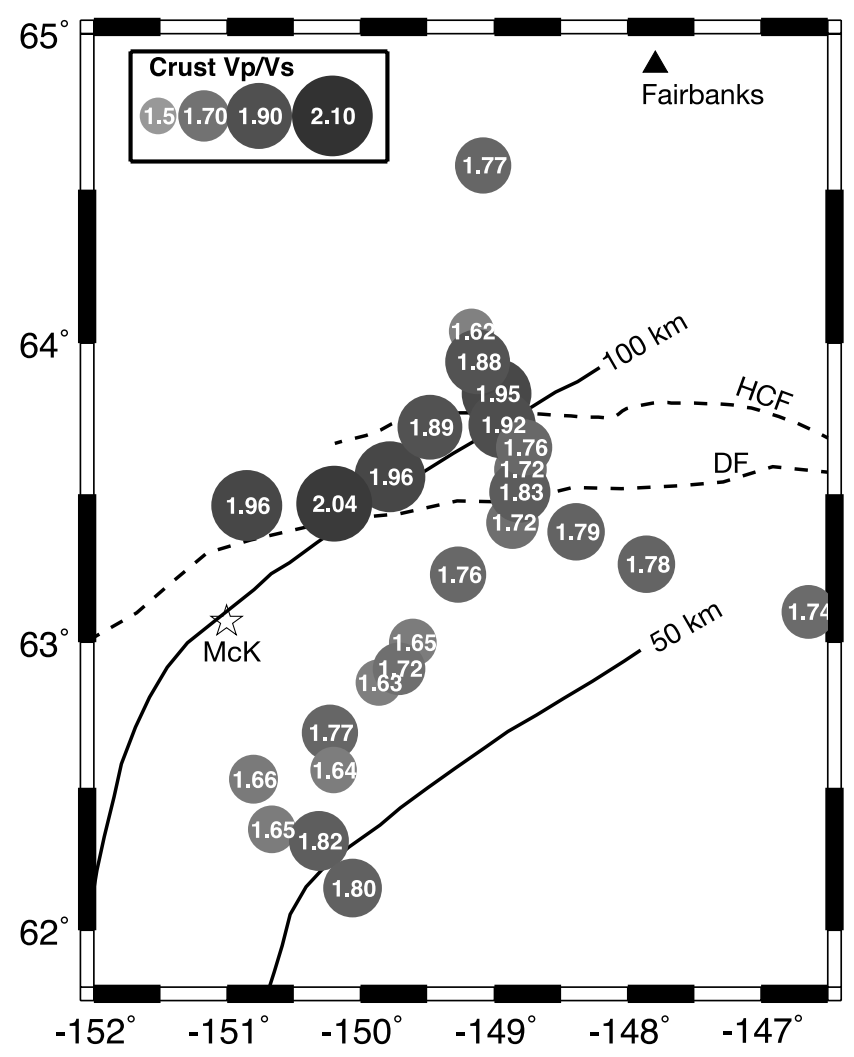

have relatively higher $\sigma_{k}$. Additionally, phases with obvious interferences or high noise are eliminated.

[19] Uncertainties in the best fitting solution are estimated by evaluating the significance of deviations of $U_{j}(z)$ from $U_{0}$, as a function of $j$ and $z$. The stack $U_{j}$ represents a weighted average of $N K$ values of $s_{i j k}$ at each $z$, which by the central limit theorem should be approximately normally distributed; $K$ is the number of phases actually included in the stack. A confidence limit for $U_{0}$ can be evaluated via the test statistic

$$
T(j, z)=\frac{U_{0}-U_{j}(z)}{S / \sqrt{N K-2}},
$$

where $S$ is the estimated standard deviation of individual traces, pooled from the $\sigma_{k} ; T$ should have a standard Student $t$ distribution with $N K-2$ degrees of freedom. A one-sided $t$ test establishes a level $U_{j}$, giving a confidence region in $z$ and $V p / V_{s}$ (Figure 6). Multiple maxima occasionally appear, for example when the Moho and slab are close, so obviously incorrect peaks are supressed. We contour the $85 \%$ confidence level, so that its maximum bounds in $z$ or $V p / V s$ approximate a $95 \%$ marginal confidence limit for individual parameters.

\section{Results}

\subsection{Crust}

[20] Crustal thickness is estimated by stacking SV phases for 10-46 events at each station (Figure 3, inset). We set

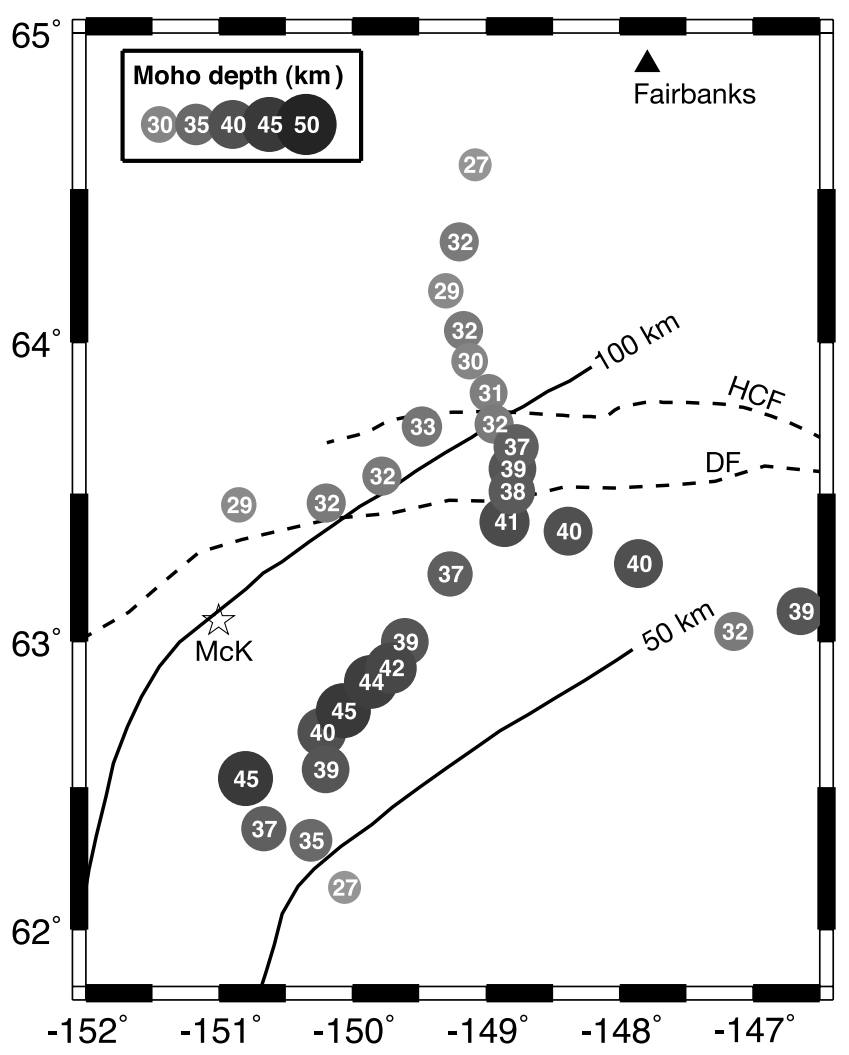

Figure 7. Results for crustal inversions, plotted at station location. (left) $V p / V s$; (right) crustal thickness. Solid lines indicate WBZ isobaths labeled by depth; dashed lines indicate major crustal faults. DF, Denali Fault; HCF, Hines Creek Fault; McK, summit of Mount McKinley. 


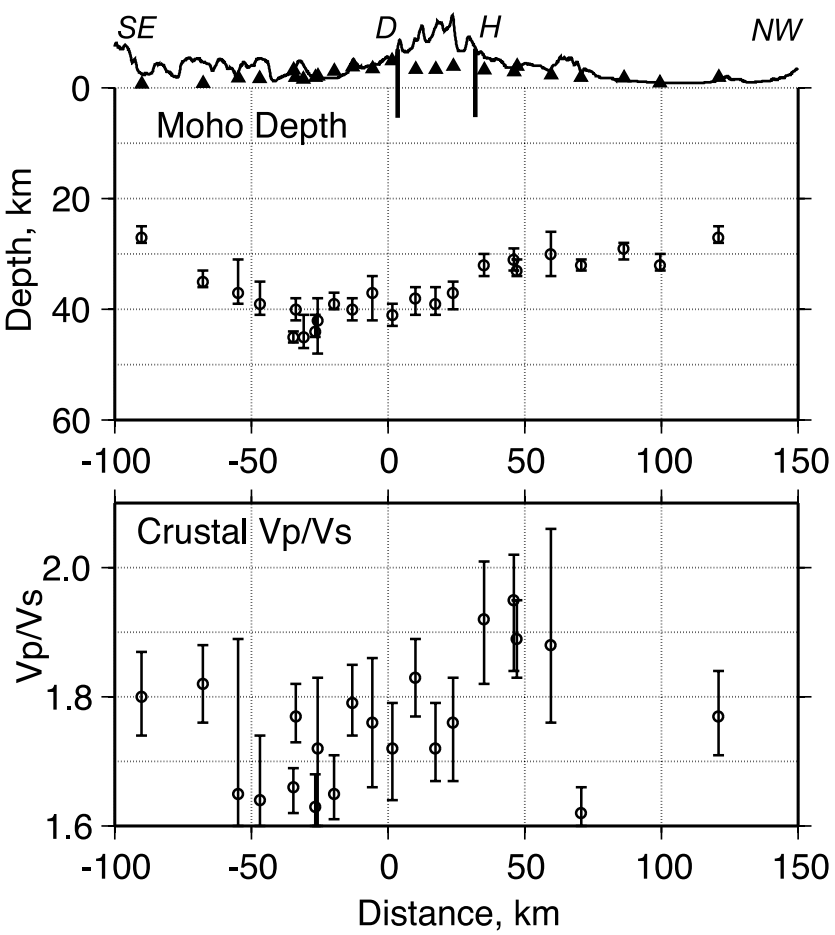

Figure 8. Cross section with Moho depths and crustal $\mathrm{Vp} /$ $V s$, with formal $95 \%$ confidence estimates. Cross section location is shown on Figure 3, with distance of $0 \mathrm{~km}$ at station RND. Note vertical exaggeration. Top shows topography and station locations (triangles), with $10 \mathrm{X}$ vertical exaggeration. D, Denali Fault; H, Hines Creek Fault.

$V p=6.5 \mathrm{~km} \mathrm{~s}^{-1}$ in the crust, following one-dimensional arrival time inversion [Stachnik, 2002]. Sensitivity tests suggest that this average velocity should be accurate to within $3 \%$, so uncertainties in velocity contribute at most $\pm 1.2 \mathrm{~km}$ to Moho depth. After applying the moveout correction and prior to stacking, a low-pass Gaussian filter is applied to the traces in the depth domain with a $0.05-0.08 \mathrm{~km}^{-1}$ width, so that all phases have the same wave number content when stacked. Inversions for Moho depth and average crustal $V_{p} / V_{s}$ are shown in Figures 7 and 8 and listed in Table 1.

[21] Coherent phases occasionally appear before the Moho arrival, indicating discontinuities within the crust. In principle these phases have different moveout than the Moho arrivals, but sometimes their presence can interfere, either increasing the uncertainty bounds or giving secondary maxima in stack amplitude. Signals at northern stations (NNA, AND and SOB) are strongly affected by reverberation in the $1-2.5 \mathrm{~km}$ thick Nenana basin, which interferes strongly with Pms but not Ppms or Psms. For these stations, stacks incorporating Pms show weak coherence but can overestimate crustal thickness significantly. In synthetic tests for basins $2-3 \mathrm{~km}$ thick, the average crustal $V p / V s$ is overestimated by $0.05-0.20$, and Moho depths estimated from Pms alone are 5-12 km greater than observed. However, when the correct $V p / V s$ is used the Ppms phase gives a depth accurate to within $1 \mathrm{~km}$, indicating that the basin reverberation does not interfere with free-surface multiples. In inversions of actual data, we fix $V p / V s$ for these two stations to values derived from stations outside the basin, and do not use Pms. This example shows that stacking techniques must be applied carefully where basins are present.

[22] Moho depths (Figures 7 and 8 and Table 1) generally agree with those by Veenstra et al. [2006], and show a thicker crust south of the Denali fault and $\sim 10 \mathrm{~km}$ thinner crust north it. Individual Moho depths vary from 27 to $45 \mathrm{~km}$, while the $V p / V s$ ratio varies from 1.62 to 2.04 with an average of 1.78 , slightly above the global average for continental crust of 1.76 [Christensen, 1996]. When averaged over nearby stations in tectonically similar regions (groupings on Table 1), $\mathrm{Vp} / \mathrm{Vs}$ ranges from $1.71 \pm 0.03$ south of the Denali fault to $1.95 \pm 0.04$ along the Hines Creek Fault, a major Mesozoic suture. The Hines Creek Fault, merging with the Denali Fault east of the study area, also appears to demark the 10-15 km northward decrease in crustal thickness [Brocher et al., 2004].

[23] Ai et al. [2005] applied the method of Zhu and Kanamori [2000] to a subset of the BEAAR data set to measure crustal thickness. They analyzed only 18 of the 29 stations shown here, including very few from the southern half of the array. Except for two southern stations, our Moho depths agree with theirs with mean discrepancy of $0.3 \mathrm{~km}$. The $V p / V_{S}$ estimates correlate poorly between the two studies for individual stations $\left(\mathrm{R}^{2}=0.25\right)$, but when averaged by the regional groupings (Table 1 ) they show good correlation $\left(\mathrm{R}^{2}=0.78\right)$, supporting our inference that regional trends are robust despite high interstation variability. Ai et al. also applied a low-frequency stacking method to mantle structure, resulting in a low-resolution image of the slab that does not take into account the strong ray bending produced by dipping layers.

[24] Overall, Moho depths show smooth variation between nearby stations but $V p / V s$ estimates vary considerably, even though signals from adjacent stations sample much the same material. The variations are all within the uncertainties (Figure 8 and Table 1), suggesting that the scatter is not a real effect but a result of random errors characterized by the error estimates. Averaging of $V p / V s$ for nearby stations increases the number of measurements per average and reduces uncertainties to $0.03-0.05$, more useful and less than the regional variations seen. Hence only regional averages of $V p / V s$ should be interpreted.

\section{2. $P$ Wave Velocity in the Mantle Wedge}

[25] We invert $P n$ traveltimes recorded by BEAAR from regional earthquakes in Alaska to determine upper mantle $P$ velocity. Inversions include 45 earthquakes shallower than $50 \mathrm{~km}$ and outside of the network region, separated into three azimuthal quadrants. Within each data subset, a constant $P n$ velocity and event source terms are determined by least squares inversion of traveltimes, after correcting for the crustal thickness variations in Table 1. This method only has sensitivity to differential traveltimes, so constrains average $P n$ velocities under the array. The $P n$ velocities are $7.82 \pm 0.10$ and $7.89 \pm 0.02 \mathrm{~km} \mathrm{~s}^{-1}$ for north and southwest back azimuths, respectively ( $2 \sigma$ uncertainties). Events from southeast back azimuths give a velocity of $7.71 \pm 0.08 \mathrm{~km} \mathrm{~s}^{-1}$, presumably lower because of refraction in the dipping slab. The mean of the above results, $7.81 \mathrm{~km} \mathrm{~s}^{-1}$, is used as $V p$ for the wedge in calculating 
Table 1. Results From Inversions, by Station

\begin{tabular}{|c|c|c|c|c|c|c|c|c|c|c|}
\hline Site $^{\mathrm{a}}$ & Crust $V p / V s$ & $\mathrm{CI}^{\mathrm{b}}$ & Crust Moho Depth, km & $\mathrm{CI},{ }^{\mathrm{b}} \mathrm{km} \mathrm{I}$ & Mantle $V p / V_{S}$ & Slab & Moho Depth, km & $\mathrm{CI},{ }^{\mathrm{b}} \mathrm{km}$ & LVZ Width, ${ }^{\mathrm{c}}$ & ${ }^{c} \mathrm{~km} N^{\mathrm{d}}$ \\
\hline \multicolumn{11}{|c|}{ Northern } \\
\hline NNA & 1.77 & $+0.07 /-0.06$ & 26.7 & $+1.5 /-1.4$ & - & - & - & - & - & 31 \\
\hline AND & 1.76 & - & 31.9 & $+1.2 /-1.5$ & - & - & - & - & - & 14 \\
\hline SOB & 1.70 & - & 29.4 & $+1.4 /-1.5$ & 1.69 & - & 161.5 & $+3.3 /-5.3$ & $14 \pm 5$ & 15 \\
\hline $\mathrm{RCK}$ & 1.62 & $+0.04 /-0.02$ & 32.2 & $+1.1 /-1.2$ & 1.67 & $+0.01 /-0.01$ & 154.5 & $+2.8 /-2.6$ & $26 \pm 3$ & 24 \\
\hline SLT & 1.88 & $+0.18 /-0.12$ & 30.1 & $+4.3 /-4.3$ & 1.61 & $+0.04 /-0.01$ & 143.5 & $+3.1 /-4.1$ & $21 \pm 5$ & 13 \\
\hline GNR & 1.95 & $+0.07 /-0.11$ & 30.6 & $+2.0 /-1.3$ & 1.65 & $+0.10 /-0.07$ & 120 & $+3.9 /-4.6$ & $16 \pm 6$ & 21 \\
\hline MCK & 1.92 & $+0.09 /-0.10$ & 31.7 & $+2.0 /-2.0$ & 1.67 & $+0.07 /-0.06$ & 118.5 & $+3.3 /-2.8$ & $17 \pm 4$ & 40 \\
\hline \multicolumn{11}{|c|}{ Central Alaska Range } \\
\hline YAN & 1.76 & $+0.07 /-0.09$ & 37.2 & $+3.1 /-2.3$ & 1.71 & $+0.06 /-0.05$ & 114 & $+3.4 /-3.1$ & $15 \pm 7$ & 41 \\
\hline CAR & 1.72 & $+0.07 /-0.05$ & 38.7 & $+2.6 /-2.7$ & 1.70 & $+0.07 /-0.12$ & 112.5 & $+9.7 /-3.8$ & $13 \pm 7$ & 16 \\
\hline SLM & 1.83 & $+0.06 /-0.06$ & 38.5 & $+2.2 /-2.3$ & 1.66 & $+0.10 /-0.09$ & 109 & $+7.3 /-5.4$ & $15 \pm 7$ & 14 \\
\hline RND & 1.72 & $+0.07 /-0.08$ & 41.1 & $+2.1 /-1.9$ & 1.79 & $+0.08 /-0.06$ & 104.5 & $+2.6 /-3.1$ & $15 \pm 3$ & 42 \\
\hline GOO & 1.76 & $+0.10 /-0.10$ & 37.3 & $+4.3 /-3.6$ & 1.60 & $+0.09 /-0.04$ & 106.5 & $+4.0 /-5.2$ & $17 \pm 5$ & 35 \\
\hline \multicolumn{11}{|c|}{ Southern (Slab < 80 km Deep) } \\
\hline HURN & 1.65 & $+0.06 /-0.03$ & 38.8 & $+1.3 /-1.8$ & 1.89 & $+0.07 /-0.13$ & 95.5 & $+5.5 /-2.9$ & $25 \pm 5$ & 45 \\
\hline PYY & 1.72 & $+0.11 /-0.12$ & 42.5 & $+5.0 /-4.1$ & 1.89 & $+0.10 /-0.19$ & 87.5 & $+3.5 /-2.7$ & $23 \pm 4$ & 14 \\
\hline MHR & 1.63 & $+0.05 /-0.03$ & 43.6 & $+1.6 /-2.3$ & 1.72 & $+0.11 /-0.10$ & 95.5 & $+3.5 /-3.0$ & $24 \pm 4$ & 22 \\
\hline FID & 1.72 & - & 44.6 & $+2.7 /-3.3$ & 1.78 & $+0.09 /-0.08$ & 90.5 & $+2.2 /-2.6$ & $24 \pm 3$ & 10 \\
\hline BYR & 1.77 & $+0.05 /-0.04$ & 40.0 & $+1.9 /-1.9$ & 1.68 & $+0.07 /-0.04$ & 91.5 & $+1.5 /-1.8$ & $14 \pm 2$ & 46 \\
\hline WOLF & 1.64 & $+0.10 /-0.04$ & 38.7 & $+2.0 /-3.3$ & 1.74 & - & 92 & $+5.7 /-3.2$ & $20 \pm 6$ & 12 \\
\hline TCE & 1.82 & $+0.06 /-0.06$ & 34.6 & $+1.8 /-1.7$ & 1.74 & - & 79.5 & $+2.6 /-3.3$ & $20 \pm 4$ & 18 \\
\hline TLKY & 1.80 & $+0.07 /-0.06$ & 26.7 & $+1.5 /-1.6$ & 1.76 & - & 87 & $+3.5 /-13.5$ & - & 37 \\
\hline PVE & 1.65 & $+0.24 /-0.05$ & 36.6 & $+2.4 /-5.4$ & 1.76 & - & 93 & $+4.5 /-3.8$ & $32 \pm 6$ & 8 \\
\hline PVW & 1.66 & $+0.03 /-0.04$ & 44.9 & $+1.6 /-1.3$ & 1.80 & $+0.27 /-0.15$ & 94 & $+6.0 /-6.1$ & $26 \pm 7$ & 24 \\
\hline \multicolumn{11}{|c|}{ Western Cross Line } \\
\hline WON & 1.96 & $+0.14 /-0.10$ & 29.4 & $+2.4 /-3.4$ & 1.87 & $+0.06 /-0.08$ & 125 & $+5.1 /-3.7$ & $14 \pm 5$ & 34 \\
\hline SBL & 2.04 & $+0.06 /-0.12$ & 32.3 & $+2.6 /-1.9$ & 1.73 & $+0.20 /-0.07$ & 119 & $+3.9 /-6.4$ & $15 \pm 5$ & 16 \\
\hline EFS & 1.96 & $+0.07 /-0.06$ & 31.7 & $+1.6 /-1.5$ & 1.74 & $+0.11 /-0.04$ & 121 & $+3.5 /-6.5$ & $12 \pm 6$ & 23 \\
\hline SAN & 1.89 & $+0.06 /-0.06$ & 32.7 & $+1.3 /-1.5$ & 1.74 & $+0.05 /-0.09$ & 121.5 & $+8.2 /-3.3$ & $20 \pm 6$ & 35 \\
\hline \multicolumn{11}{|c|}{ Eastern Cross Line } \\
\hline DH1 & 1.79 & $+0.06 /-0.05$ & 40.2 & $+2.1 /-2.1$ & 1.82 & $+0.25 /-0.08$ & 94 & $+2.4 /-4.9$ & $21 \pm 4$ & 36 \\
\hline DH2 & 1.78 & $+0.06 /-0.07$ & 40.4 & $+2.9 /-2.4$ & 1.74 & $+0.12 /-0.22$ & 91 & $+10.3 /-4.4$ & $27 \pm 8$ & 14 \\
\hline DH3 & 1.76 & - & 32.1 & $+3.2 /-2.4$ & 1.58 & $+0.13 /-0.08$ & 87.5 & $+7.2 /-5.2$ & $29 \pm 7$ & 24 \\
\hline $\mathrm{CZN}$ & 1.74 & $+0.08 /-0.07$ & 39.0 & $+2.4 /-2.4$ & - & - & - & - & - & 23 \\
\hline
\end{tabular}

${ }^{\mathrm{a}}$ Station locations shown on Figure 3.

${ }^{\mathrm{b}} \mathrm{CI}, 95 \%$ confidence interval; dash indicates parameter fixed in inversion.

${ }^{c}$ Corrected for difference between LVZ and moveout velocities; 95\% confidence bounds from linearized error propagation.

${ }^{\mathrm{d}}$ Number of events used.

moveout corrections, slightly lower than the $7.85-8.0 \mathrm{~km}$ $\mathrm{s}^{-1} \quad$ estimated in a previous $P n$ inversion [McNamara and Pasyanos, 2002]. Velocity tomography results [EberhartPhillips et al., 2006; Rossi, 2004], show considerable complexity within the wedge, with $V p$ ranging from 7.5 to $8.2 \mathrm{~km} \mathrm{~s}^{-1}$. Varying the assumed $V p$ by $0.2 \mathrm{~km} \mathrm{~s}^{-1}$ will systematically change depth to slab by $1-2 \%$, or $<2 \mathrm{~km}$ depending upon slab depth (Table 2).

\subsection{Mantle Wedge Inversion}

[26] We invert for mantle wedge structure, as described above, setting parameters as shown on Figure 5 and from crustal inversions (Table 1). Where not directly estimated, crustal $V p / V s$ is interpolated from nearby stations. The stacking is tuned to maximize the amplitude of the major positive arrival from the base of the LVZ, which is probably the Moho of the subducted crust. In numerical tests this

t2.1 Table 2. Sensitivity Tests for Station MCK

\begin{tabular}{|c|c|c|c|c|c|}
\hline Parameter & Value Used in Inversion & Bound $^{\mathrm{a}}$ & Source of Constraints & $V p / V_{s}$ Variation $^{\mathrm{b}}$ & Slab Depth Variation, ${ }^{\mathrm{b}} \mathrm{km}$ \\
\hline Crust thickness, km & 31.7 & 2.0 & this analysis & -0.005 & -0.5 \\
\hline Crust $V p, \mathrm{~km} \mathrm{~s}^{-1}$ & 6.5 & 0.2 & tomography & 0.000 & 0.5 \\
\hline Crust $V p / V s$ & 1.92 & 0.10 & this analysis & -0.030 & 0.2 \\
\hline Mantle wedge $V p, \mathrm{~km}$ & 7.81 & 0.2 & $P n$ inversion & -0.005 & -0.2 \\
\hline LVZ thickness, km & 14 & 2.5 & this analysis & -0.005 & -0.5 \\
\hline $\mathrm{LVZ} V p, \mathrm{~km} \mathrm{~s}^{-1}$ & 7.0 & 0.3 & Ferris et al. [2003] & 0.000 & -1.0 \\
\hline $\mathrm{LVZ} V p / V_{S}$ & 1.73 & 0.07 & Ferris et al. [2003] & -0.010 & 0.2 \\
\hline 2.10 Slab dip, deg & 25 & 2 & Abers et al. [2006] & -0.025 & 1.3 \\
\hline
\end{tabular}

t2.11 ${ }^{\mathrm{a}}$ Maximum reasonable error in value from measured uncertainties.

t2.12 ${ }^{\mathrm{b}}$ Sign indicates sign of covariance between parameter and estimated value. 

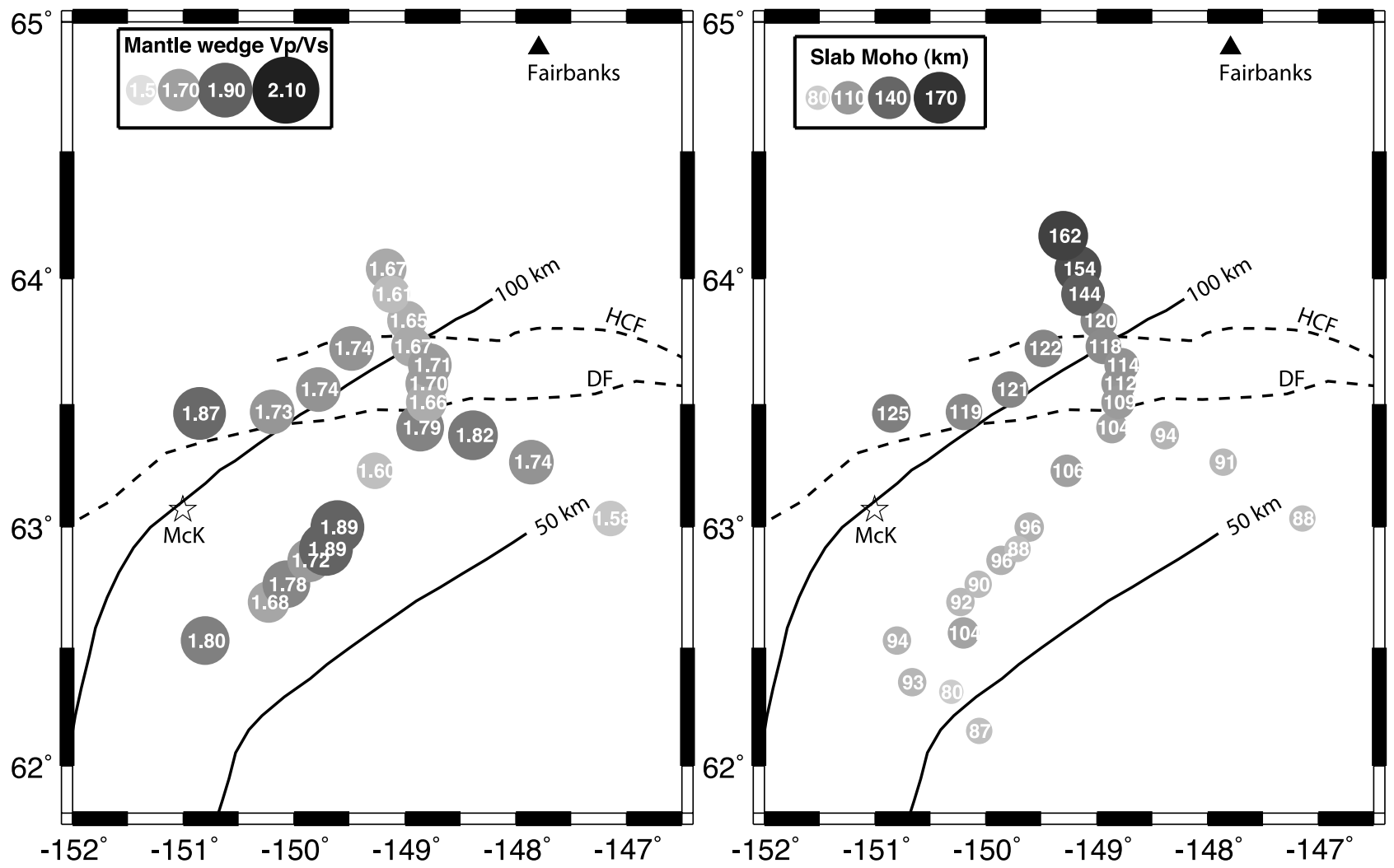

Figure 9. Inversion results for mantle wedge. (left) $\mathrm{Vp} / V_{s}$; (right) depth to bottom of LVZ (inferred Moho of subducted crust). Abbreviations and symbols are same as Figure 8.

phase is consistent in polarity and amplitude for a wide range of $V p / V s$ in the mantle wedge, unlike the arrival from the top of the LVZ, so for most phases the sign correction does not vary with wedge $V p / V s$. The exception is the $S H$ component of Psxs, so this phase is not used, giving $K=5$ phases per stack. We also estimate thickness of the LVZ from the timing of the prominent negative-amplitude anomaly above the slab Moho arrival (Figure 6).

[27] Inversion results (Figures 9 and 10 and Table 1) show $V p / V s$ varies from $1.58(+0.13 /-0.08)$ to $1.89(+0.07 /$ -0.13 ), with most measurements less than 1.75. In the wedge $V p / V s$ shows less variation than in the crust and smaller uncertainties, probably because signals travel longer. The inversion does not constrain $V p / V s$ at the southernmost stations, probably because the distance between the top of the slab and the base of the crust is small $(<20 \mathrm{~km})$, so for those sites $V p / V_{S}$ is held fixed and only slab depth is estimated. At the northernmost two sites, NNA and AND, slab conversions are expected at depths greater than $160 \mathrm{~km}$ but could not be identified, nor could they be seen at the easternmost site $(\mathrm{CZN})$. Among the remaining stations, the highest values of $V p / V s$ occur where the slab is less than $80 \mathrm{~km}$ deep, and at station WON. The northern stations, north of the Hines Creek Fault, exhibit very low $V p / V_{S}(1.61-1.69)$. The low $V p / V_{s}$ show small uncertainties (0.01-0.07) and consistency between adjacent stations.

[28] The slab depth estimates also agree with those based on waveform inversion [Ferris et al., 2003] (Figure 10), although the slab here is deeper for the northernmost three stations. This discrepancy is expected from the trade-off between depth and $V p / V_{s}$; Ferris et al. assumed $V p / V s=$ 1.76 in the mantle. The LVZ has roughly constant thickness (13-26 km; Figure 10), similar to Ferris et al.

\subsection{Inversion of Artificial Data}

[29] As a test of the method we invert artificial data, numerically generated for a velocity structure matching that illustrated in Figure 5. Synthetic seismograms for dipping layers are generated following Frederiksen and Bostock [2000], with interface depths and $V p / V s$ corresponding to those determined for station MCK (Table 1), and the same ray distribution as for real data recorded at MCK. Noise is added with the same autocorrelation as actual noise prior to the $P$ arrival but with random phase. The resulting receiver functions show the expected Moho and slab arrivals (Figures 11a and 11b). Moveout corrections for the slab phases Pxs and Ppxs result in Moho reverberations that do not stack coherently, as expected given the differences in moveout correction between slab and Moho phases. The differences are strongest for $\mathrm{SH}$, which show no conversions from the flat-lying Moho but strong slab signals, much as real data. When inverted for structure, the correct slab depth, LVZ thickness and wedge $V p / V s$ are recovered (Figure 11c). Several inversions of artificial data generated in other models, not shown, showed that slab depth and LVZ thickness are recovered within $1 \mathrm{~km}$, and $V p / V s$ within 0.02 in all cases.

\subsection{Sensitivity Tests}

[30] While a number of parameters are assumed in the inversions (Figure 5), most are known sufficiently well that 


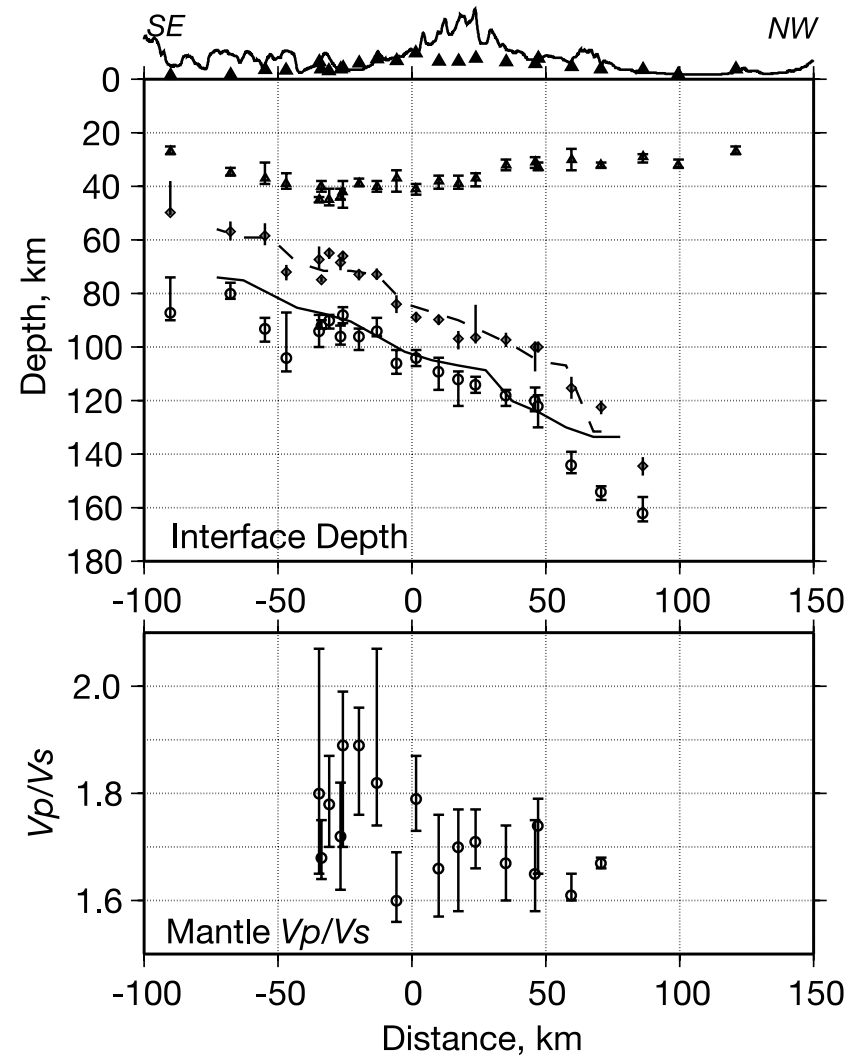

Figure 10. Cross section showing wedge inversion results. Line location and figure layout are same as Figure 8. (top) Circles show bottom of LVZ, diamonds show top of LVZ, and triangles show Moho from crustal inversion. Dashed and solid line show top and bottom, respectively, of LVZ estimated by Ferris et al. [2003], corrected for a plotting error in that paper. Note general agreement of the two studies. Topography exaggerated 10 times. (bottom) $\mathrm{Vp} / \mathrm{VS}$ estimates.

their uncertainties contribute little to the uncertainties in estimates. To illustrate this point, sensitivity tests are carried out on all principal assumed parameters for data from representative station MCK (Table 2). In each test, one parameter is varied within a range of values consistent with its uncertainties, and the data reinverted. For example, Moho depth and crustal $V p / V s$ are tested at the limits of their 95\% marginal confidence bounds (Table 1), and mantle wedge $V p$ is varied through the bounds from $P n$ inversion (section 4.2). For the preferred parameter values, mantle wedge $V p / V s=1.67+0.07 /-0.06$, and slab Moho depth is estimated as $118.5+3.3 /-2.8 \mathrm{~km}$.

[31] Changes to layer thicknesses of $P$ velocities have little effect on $V p / V s$ estimates, while slight trade-offs exist between these parameters and slab depths, resulting in $2 \mathrm{~km}$ uncertainty in slab depth (Table 2). The $V p / V s$ estimate is most sensitive to the estimated $V p / V s$ in the crust, with a trade-off roughly comparable to the ratio of mantle wedge to crustal thickness (sensitivity tests at southern stations show similar scaling of this trade-off). The average dip of the slab is constrained to $\pm 2^{\circ}$ [Ferris et al., 2003], contributing $<2 \%$ to uncertainties in estimated parameters.
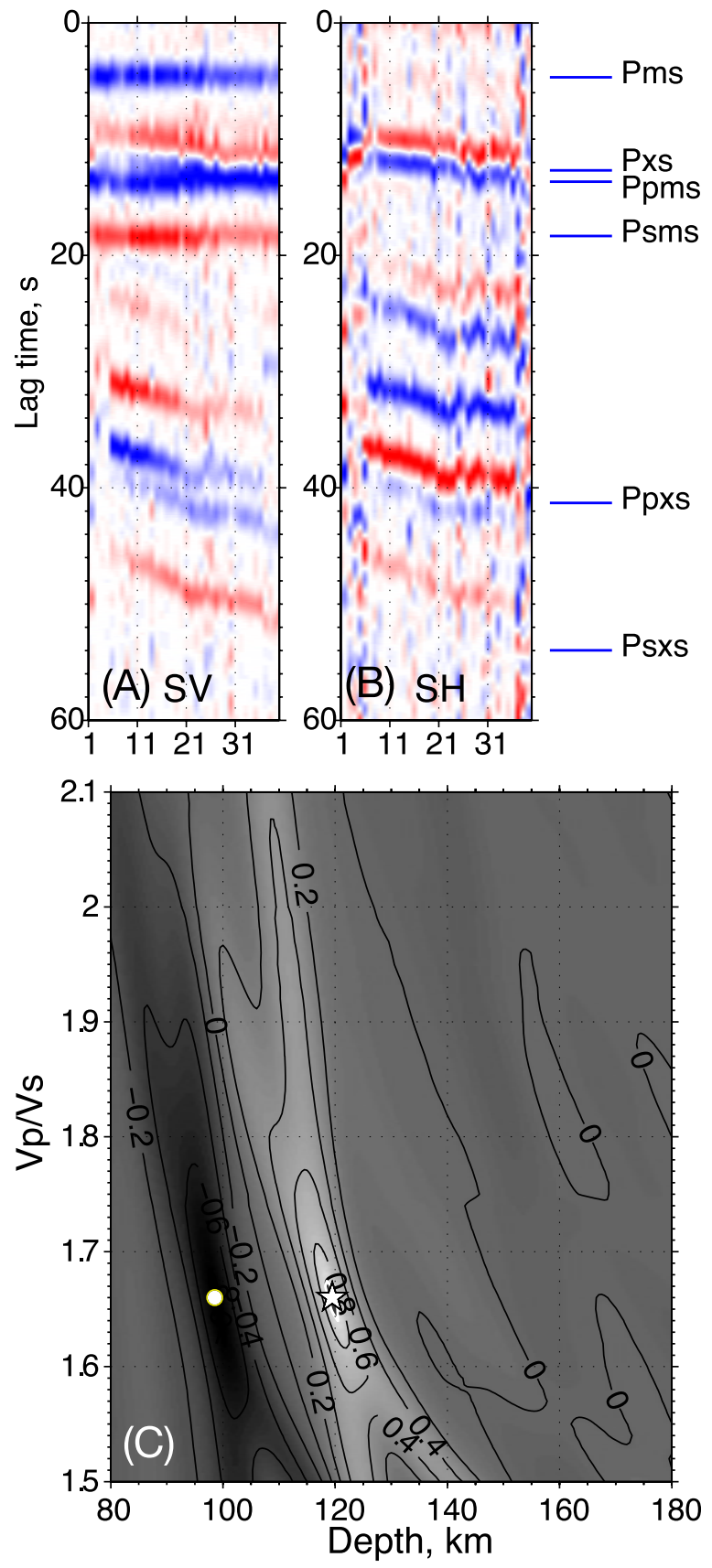

Figure 11. Synthetic test. (a) Artificial radial component receiver functions generated for a model as in Figure 5 and with noise added, for actual ray geometry recorded at station MCK. Signals processed as for actual data. Stations are plotted in order of increasing azimuth; blue shows positive amplitude arrivals, red negative. (b) Same for transverse component. Predicted phases from upper plate Moho and slab Moho shown at right for a $p=0.06 \mathrm{~s}$ $\mathrm{km}^{-1}$. Note that slab arrivals (Pxs, Ppxs, Psxs) show strong moveout with azimuth, but Moho arrivals show little moveout. (c) Inversion results for these records. Symbols are same as Figure 6. Best fitting slab Moho depth, $V p / V s$, and LVZ thickness are $119.5 \mathrm{~km}, 1.66$, and $16.6 \mathrm{~km}$, respectively, within uncertainties of the correct values of $118.5 \mathrm{~km}, 1.67$, and $17.2 \mathrm{~km}$. 


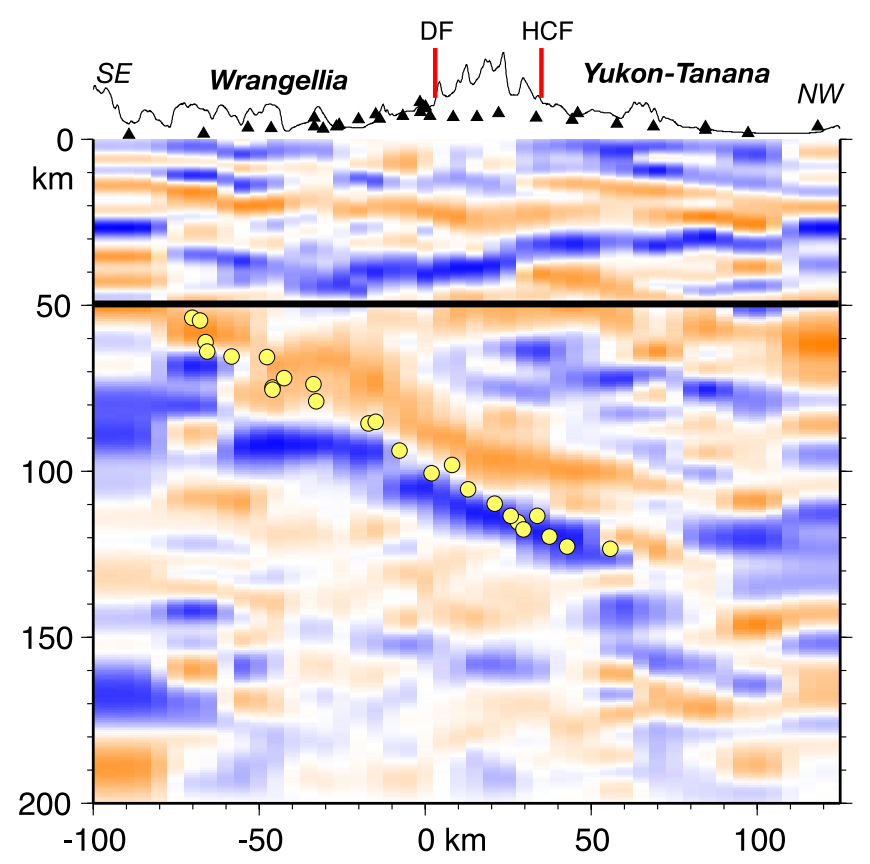

Figure 12. Image of scatterers along cross section (Figure 3). Image produced separately from crustal stacks at depths $<50 \mathrm{~km}$, and wedge stacks at 50-200 km depth. Beneath each station, stacked, moveout-corrected trace is calculated for the best $V p / V s$. Signal at each pixel is taken from averaging nearby traces at each depth, with $10 \mathrm{~km}$ lateral averaging. Blue shows positive conversions; orange shows negative. Yellow circles show earthquakes in slab [Ferris et al., 2003]. DF, Denali Fault; HCF, Hines Creek Fault. Major composite terranes are also labeled.

\subsection{Trade-offs Between Crust and Mantle $V p / V s$}

[32] The sensitivity tests suggest some trade-off between $V p / V s$ in different layers. To further explore trade-offs between $V p / V s$ in the crust and in the mantle, all mantle wedge inversions were repeated with the crustal $\mathrm{Vp} / \mathrm{Vs}$ fixed to 1.73. For the Northern stations (as defined in Table 1), this resulted in an increase of the average $V p / V_{s}$ from 1.650 to 1.688. For the Southern stations, the average $V p / V s$ changed from 1.793 to 1.797 . Some trade-off clearly exists, but it is small compared with the parameter variations observed. Furthermore, crustal $V p / V s$ is demonstrably larger than 1.73 , so these tests are extreme.

\section{Discussion}

\subsection{Crust}

[33] The thickest crust lies between stations BYR and HURN, 30-50 km south of the highest topography (Figures 7 and 8). Some of that offset may be a twodimensional effect of the irregular transect geometry; even though stations HURN to MCK lie at the highest elevations, the transect is closest to the highest topography of the Denali massif near BYR and PVW. However, the observed Moho cannot be reproduced with a simple, uniform thin elastic plate supporting topography, indicating a complicated and asymmetrical compensation process as discussed elsewhere [Veenstra et al., 2006].
[34] Crustal thicknesses on the continental Yukon-Tanana terrane, north of the Hines Creek fault, are low $(27-32 \mathrm{~km})$ and are consistent with active-source results on the same terrane farther to the east [Beaudoin et al., 1992; Brocher et al., 2004]. The results are unlikely to be affected by the presence of a thick sedimentary basin, thickest beneath SOB and AND, because the numerical tests indicate that any such bias would be toward overestimates of Moho depth (section 4.1). Isostatic balance calculations [Veenstra et al., 2006] show that the northward thinning in crustal thickness greatly exceeds that predicted by the change in elevation, requiring a lower lithospheric density north of the Denali fault.

[35] The average crustal $V p / V s$ (1.78) is slightly greater than the global average for continental crust, but close to expected for mafic rocks [Christensen, 1996; Zandt and Ammon, 1995], which are abundant in the accreted terranes forming continental Alaska. Much of the interstation variability of $V p / V s$ probably reflects noise. For Moho conversions, the waveform Fresnel zones and associated areas of sampling are comparable to station spacing, so one would expect adjacent stations to show similar $V p / V s$. As a result, regional averages of $V p / V s$ provide more insight than single-station values.

[36] Averaging over stations on similar geology, elevated $V p / V s(1.95 \pm 0.04)$ occurs at the five stations within $1-$ $10 \mathrm{~km}$ of the Hines Creek strand of the Denali Fault (Figure 7). This fault system marks perhaps the most significant geological boundary in the study area, between accreted oceanic arc terranes to the south and continental basement to the north. It represents the site of Cretaceous closure of a major ocean basin north of Wrangellia, and is associated with a north dipping belt of high electrical conductivity through much of the crust [Ridgway et al., 2002; Stanley et al., 1990]. Major crustal faults are often associated with high $\mathrm{Vp} / \mathrm{Vs}$ and high electrical conductivity [Thurber et al., 2003; Zhao et al., 1996], probably because fluids are abundant within the fault zones.

\subsection{Crustal Architecture}

[37] After estimating $V p / V s$ variations, we generate a stacked, moveout-corrected image of structure in the crust and mantle beneath each station (Figure 12). In this image, crustal moveout and $\mathrm{Vp} / \mathrm{Vs}$ are used to image at depths less than $50 \mathrm{~km}$, and moveout for a dipping slab are used to image deeper structure. The Moho shows as a clear and strong conversion, as does the slab LVZ. Several other coherent arrivals become apparent, particularly in the crust, and strong conversions appear within the mantle wedge. Because a full migration of mantle signals is subject of another paper [Rondenay et al., 2004], we only discuss the crustal structure here.

[38] A series of planar midcrustal surfaces, dipping gently to the north, can be seen across much of the array. The largest-amplitude conversion has negative polarity, indicating lower velocities below the boundary than above it. The conversion descends from $12 \mathrm{~km}$ depth at the $\mathrm{S}$ end of the profile to Moho depths near the Hines Creek fault. Similar features were imaged in the TACT active-source transect several hundred $\mathrm{km}$ to the east [Fuis et al., 1991], and were interpreted as gently dipping faults that bound terranes, perhaps relict subduction thrusts. 


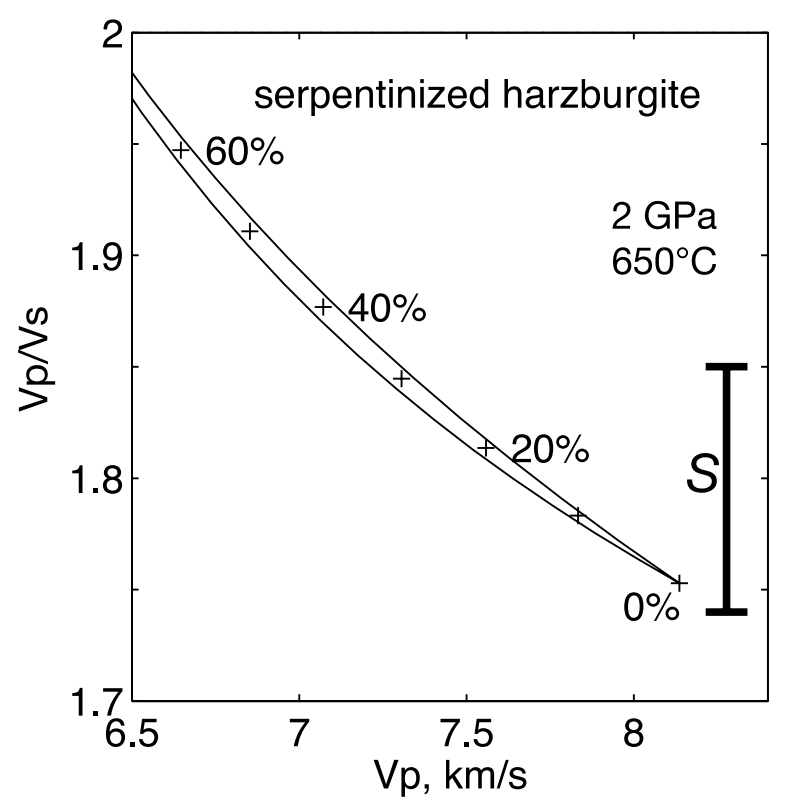

Figure 13. Predicted $V p$ and $V p / V s$ for variably serpentinized harzburgite at $2 \mathrm{GPa}$ and $650^{\circ} \mathrm{C}$. Calculations are based on composition and calculation method of Hacker and Abers [2004]. Lines show upper and lower HashinShtrikman bounds; crosses show $10 \%$ increments of serpentinization. Error bar labeled "S" denotes range in average $V p / V S$ for the mantle wedge beneath southern stations (Table 1).

[39] This kind of shingling of crust may in fact be the primary mode of crustal growth where arcs collide with continents [Cook, 1986], and indicates that the lower crustal structure is significantly offset from that at the surface. Because the BEAAR line ends to the south it is not clear what is the surface expression of this fault, but both the Contact Fault and the Border Ranges Fault (Figure 2) lie close to the updip projection of this feature. Thus the imaged faults may be fossil subduction zone thrusts, the sites of mechanical addition to the bottom of the continental crust. These shallow dipping surfaces are truncated at the Moho, which appears sharp. Either these large-scale faults are confined to the crust, or the Moho has been petrologically reset (for example through eclogite formation).

\subsection{Subducting Plate Geometry}

[40] The subducting plate here dips $25^{\circ}$ to the NW [Ferris et al., 2003], and is represented by a strong negativepolarity conversion underlain by a positive-polarity one (Figures 6 and 12). The two conversions require two interfaces bounding a LVZ, with strong velocity contrasts to at least $130 \mathrm{~km}$ depth [Ferris et al., 2003]. The thickness of the LVZ is $15-20 \mathrm{~km}$, unlike oceanic crust, but close to that observed for the oceanic Yakutat terrane now impinging at the Aleutian trench [Brocher et al., 1994]. Somewhat larger estimates of LVZ thickness emerge from stations where the slab is shallowest (Table 1), but here interferences with the upper plate Moho complicate the inversion. A similar low-velocity layer has been observed from scattered wave migration [Rondenay et al., 2004] and traveltime inversion [Eberhart-Phillips et al., 2006].

[41] The slab geometry becomes more complicated beneath the northern three stations because the conversion becomes weak. We do not estimate mantle $V p / V s$ beneath these stations. The weaker conversions indicate that the LVZ has less of a velocity contrast with the surrounding mantle, perhaps because it has largely converted to eclogite at this depth [Ferris et al., 2003].

\subsection{Shallow Wedge $V p / V s$ and Serpentinization}

[42] In the region south of the highest topography, where the slab is less than $80 \mathrm{~km}$ deep $V p / V s$ is $1.79 \pm 0.06$ when averaged over all Southern stations for which $V p / V s$ could be determined (Table 1). These are the highest mantle $V p / V s$ found. The region is the same part of the wedge showing anomalously low seismic attenuation [Stachnik et al., 2004], indicating low temperatures of perhaps $400-700^{\circ} \mathrm{C}$ [Abers et al., 2006]. Although global models predict $V p / V S$ near 1.80 in the uppermost mantle [Dziewonski and Anderson, 1981], lower temperatures here should decrease $V p / V s$ by 0.03-0.04 according to physical properties calculations [Hacker and Abers, 2004; Karato, 1993]. Thus a Vp/Vs of 1.79 slightly exceeds that expected in the southern wedge for normal mantle peridotite.

[43] Serpentine will be stable at temperatures $<700^{\circ} \mathrm{C}$ in the upper mantle [Ulmer and Trommsdorf, 1995], so could be present in the cold wedge nose. A $V p / V s$ of $1.79 \pm 0.06$ corresponds to $15 \pm 15 \%$ serpentinization for a depleted, harzburgite bulk composition (Figure 13). Within these uncertainties, the wedge tip could have as much as $30 \%$ serpentinization, or be completely unserpentinized. On the basis of long-wavelength geomagnetic anomalies Blakely et al. [2005] suggest that the mantle south of the Alaska Range is serpentinized but in a region of south of that sampled by BEAAR (dotted line on Figure 3).

[44] Greater serpentinization has been inferred in the forearc mantle beneath western Oregon, based on low $S$ velocities [Bostock et al., 2002]. In Oregon the Moho had an inverted velocity step beneath the forearc, indicating that the mantle is slower than the overlying crust, and that serpentinization may reach $50-60 \%$. In Alaska we see a fairly normal, strong Moho conversion overlying relatively fast mantle, indicating weak to absent serpentinization. Thermal models for the Cascades predict nearly complete devolatilization of the downgoing plate by the time it reaches $45 \mathrm{~km}$ depth; much of this water is available to serpentinize the wedge [Hacker et al., 2003b]. In contrast, the downgoing plate beneath Alaska should undergo much dehydration down to depths of $100-150 \mathrm{~km}$, past the cold part of the wedge [Abers et al., 2006], so dehydration is less concentrated in a single depth interval.

\subsection{Anomalously Low $V p / V s$ in the Northern Wedge}

[45] From the Denali Fault north the wedge exhibits unusually low $V p / V s$ in the range $1.6-1.7$, with the northernmost stations showing an average $V p / V s=1.65 \pm 0.03$ at 95\% confidence (Figures 9 and 10 and Table 1). Three simplifications might bias estimates here. First, the model assumes a planar dipping slab. If the slab has a downward curvature, we might expect $V p / V s$ to be overestimated, because the ray multiples have to travel a longer distance 


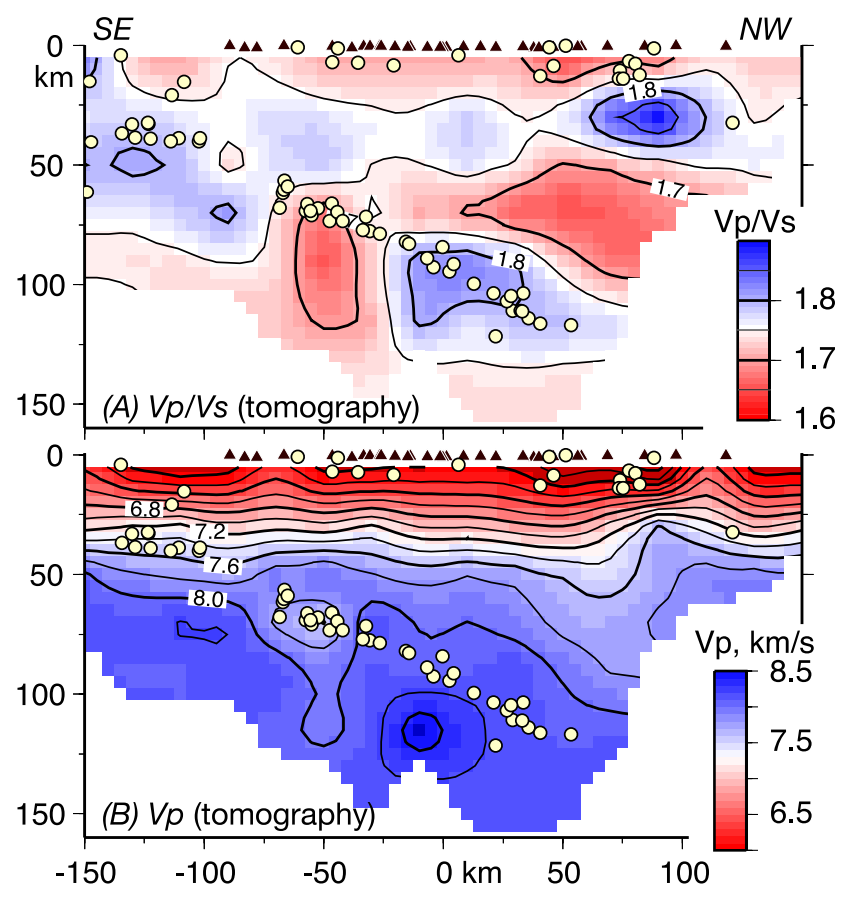

Figure 14. Traveltime inversion from local data for $V p$ and $V p / V s$ and comparison with receiver function results. Cross section location is same as Figure 8. (a) Traveltime inversion results for $V p / V s$; data are matching sets of local $P$ and $S$ arrival times using the same ray paths and parameterization as Stachnik et al. [2004]. Circles show earthquakes, triangles show stations, and colored region denotes high resolution. (b) Corresponding $P$ velocities from same inversion. Note region in mantle wedge of $V p / V s$ $<1.70$, in both receiver functions and tomography.

than the direct conversion, which would bias upward the $V p / V s$. Geometric calculations suggest that this effect is very small $(<1 \%)$ for the slight curvature observed, although full numerical simulation of this effect has not been done. Seismicity indicates that along-strike curvature is even less beneath the array. A second possibility is that anisotropy biases $V s$. Most of the earthquakes used in the inversion are concentrated in a back azimuth window of $255^{\circ}-280^{\circ}$, so most of the rays arrive parallel to the strike of the slab. Shear wave splitting measurements suggest slab-parallel fast directions in the deeper wedge, with 3-5\% azimuthal anisotropy [Christensen et al., 2003], and the stacks for single Pxs phases indicate that $S V$ precedes $S H$ by $0.3-0.6 \mathrm{~s}$ for some northern stations, indicating that some anisotropy may be present. However, the inversion includes both of these signals with roughly equal weights, and the $10 \%$ variations in $V p / V S$ we see are 2-3 times that expected for the $3-5 \%$ anisotropy inferred from splitting. Third, overestimates in crustal $V p / V s$ may trade off with mantle wedge values. As discussed in section 4.4, this effect could bias downward $V p / V s$ by at most 0.03 and probably much less because crustal $V p / V_{S}$ is well constrained. Thus the low $V p / V s$ appear to be significant.

[46] As an independent test of the low $V p / V s$ ratio, we compare the receiver functions to velocity estimates from traveltime tomography (Figure 14). The velocities are derived from a joint inversion for hypocenters and $3 \mathrm{D}$ velocity structure using the method of Roecker [1993], with the same parameterization and events as Stachnik et al. [2004]. To minimize biases in $V p / V s$ due to differing resolution of $P$ and $S$, data were used only where both a $P$ and $S$ arrival could be included for each event-station pair [Saltzer et al., 2004]. For similar reasons we use only those ray paths for which attenuation could be measured, so the ray coverage is identical to Stachnik et al. [2004] as is the resolution. The reader is referred to that study for an assessment of this image.

[47] A large part of the mantle wedge, corresponding to a WBZ $>90 \mathrm{~km}$ deep, has $V p / V_{s}$ between 1.65 and 1.70 from tomography. While features smaller than $20-30 \mathrm{~km}$ are not well resolved [Stachnik et al., 2004], this low-Vp/Vs feature appears to lie entirely within the mantle wedge, perhaps the upper half of it. This region closely resembles that exhibiting low $V p / V_{S}$ in receiver functions, both in lateral extent and the amplitude of $V p / V s$. One independent analysis of traveltime data also show low $V p / V s(1.65-1.70)$ for this part of the mantle wedge [Eberhart-Phillips et al., 2006]. Thus the low Poisson's ratio wedge is observed in two independent data sets, confirming the validity of the results presented here.

\subsection{Possible Explanations for Low Wedge $V p / V s$}

[48] Low $V p / V s \quad(<1.70)$ for the mantle is difficult to explain with most standard models of mantle composition. Typically, the uppermost mantle has $V p / V s$ near 1.80 as in global models [Dziewonski and Anderson, 1981], consistent with typical garnet-or spinel-peridotites (Figure 15). Similar low $V p / V s$ have been reported in two other subduction zone wedges, in the flat slab segment of the Andes [Wagner et al., 2005] and in the Kurile back arc [Zheng and Lay, 2006], but high $V p / V s$ is more typical [e.g., Zhang et al., 2004]. High, near-solidus temperatures are likely present in the northern parts of the Alaska wedge [Abers et al., 2006], but increases in temperature should act to raise $V p / V s$, as would the presence of melt in most realistic geometries [Koper et al., 1999; Takei, 2002]. Compositional variations of peridotites probably cannot produce the low $V p / V s$, as most mantle minerals exhibit $V p / V s$ above 1.75 and all above 1.71 (Figure 15). The lowest $V p / V s$ correspond to $\mathrm{Mg}$ endmembers of olivine and orthopyroxene, possibly significant components in regions of highly depleted mantle following melt extraction. To explain low $V p / V s$ beneath the Andes, where the subducting plate is virtually flat and volcanism is absent, Wagner et al. [2005] propose that orthopyroxenite is abundant in much of the mantle, which would require considerable silica addition such as by metasomatism from slab-derived fluids. However, even pure enstatite (the $\mathrm{Mg}$ end-member orthopyroxene) has $V p / V_{s}=1.71$ at relevant conditions [Angel and Jackson, 2002; Hacker and Abers, 2004], and observations both here and in the Andes show $V p / V s<1.70$. It is possible that reported pressure derivatives of compressibility are in error, allowing for lower $V p / V_{S}$ in enstatite, as some experimental data are contradictory (L. Wagner, personal communication, 2005). If the experimental constraints are indeed in error, then it is possible that highly depleted mantle may produce the observed $V p / V s$, but that remains to be proven.

[49] Among major rock-forming minerals, only quartz has $V p / V s<1.70$ at upper mantle pressures [Christensen, 


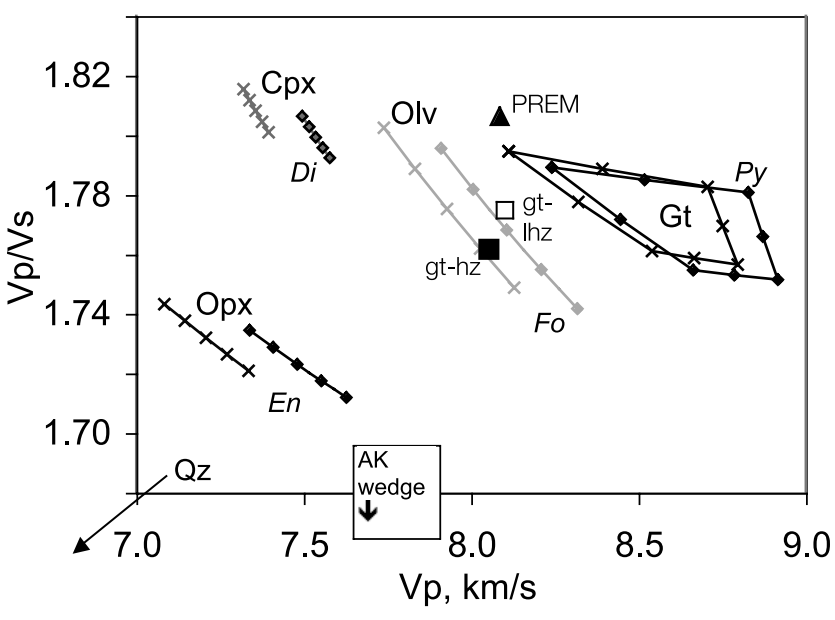

Figure 15. Predicted seismic velocities for major mantle minerals at $2 \mathrm{GPa}$ (66 km depth), from Hacker and Abers [2004]. Velocities calculated at $900^{\circ} \mathrm{C}$ (diamonds) and $1200^{\circ} \mathrm{C}$ (crosses), for minerals garnet (Gt), olivine (Olv), clinopyroxene $(\mathrm{Cpx})$, orthopyroxene $(\mathrm{Opx})$, and quartz $(\mathrm{Qz})$, including their respective $\mathrm{Mg}$ end-members pyrope (Py), forsterite (Fo), diopside (Di) and enstatite (En). For Olv, Cpx, and Opx, compositions follow Mg-Fe solid solution between $80 \%$ and $100 \% \mathrm{Mg} /(\mathrm{Mg}+\mathrm{Fe})$. For $\mathrm{Gt}$, compositions vary between end-members containing 10 $90 \%$ almandine ( $\mathrm{Fe}$ end-member), 5-50\% grossular $(\mathrm{Ca}$ end-member) and 10-90\% Py, a range that includes many common mafic and ultramafic rocks [Hacker et al., 2003a]. Increasing $\mathrm{Fe}$ or increasing temperature increases $\mathrm{Vp} / \mathrm{Vs}$ and decreases $V p$. At $900^{\circ} \mathrm{C}$, Qz has $V p=6.02 \mathrm{~km} \mathrm{~s}^{-1}$ and $V p /$ $V_{S}=1.59$. Also shown are calculated velocities at $900^{\circ} \mathrm{C}$ for garnet-lherzolite (gt-lhz) and garnet-harzburgite (gt-hz) compositions of Hacker et al. [2003a], and global model PREM at $66 \mathrm{~km}$ depth [Dziewonski and Anderson, 1981]. Mantle $V p / V s$ less than 1.70 cannot be explained by any mineral common to peridotites or mafic eclogites and may require significant Qz.

1996; Hacker et al., 2003a]. In sufficiently Si-rich rocks, quartz will be stable at pressures below 2.5-3 GPa depending upon temperature [Akaogi et al., 1995]. Although peridotites are undersaturated with respect to silica it is possible that the long history of subduction has introduced silicic crustal material into the wedge, either through metasomatism by slab derived fluids or by subduction of island arc related rocks of more felsic bulk composition. The latter scenario also has been proposed by Eberhart-Phillips et al. [2006], who see similar $V p / V_{S}$ in traveltime inversion results for the Alaska mantle. While the bulk composition of such a rock would be difficult to constrain on the basis of seismic velocities alone, physical properties calculations [Hacker and Abers, 2004] show that 15-30\% quartz, when combined with various concentrations of garnet and orthopyroxene, could produce the requisite material. Given the potentially wide range of materials that may have been subducted over the history of accretion here [Ridgway et al., 2002] it is difficult to know if this is realistic. Deep subduction of a Mesozoic flysch basin has been suggested on the basis of magnetic observations [Stanley et al., 1990], which may have fairly silicic bulk composition. Such material was likely subducted to mantle depths during collision, injecting silicic upper crustal rocks into the mantle wedge. The buoyancy of such low-density material, once it entered the mantle, may play an important role in allowing it to mix with the uppermost mantle for example through compositionally driven diapirism [Gerya and Yuen, 2003]. Thus the uppermost mantle in a region of repeated terrane accretion may be quite different in composition from normal suboceanic mantle.

[50] In summary, the low $V p / V s$ values seem to be real, and consistent with other observations, both in Alaska and elsewhere. While the cause of such low ratios is not well understood, several new observations suggest that it may be an occasional feature of subduction, particularly where volcanism is absent. Low $V p / V s(<1.7)$ may require substantial quartz be present in some fashion, given the present understanding of mineral physical properties.

\section{Conclusions}

[51] We present a new method for inverting receiver functions for depth to interfaces and the $V p / V s$ above them in the case of dipping layers. The method makes use of the linear relationship between traveltimes and interface depths to generate moveout corrections from several phases interacting with the same interface, and stacks signals to generate parameter estimates and uncertainties. We apply the method to broadband signals recorded by the BEAAR experiment in central Alaska, to estimate Moho depth, crustal $V p / V s$, LVZ depth and thickness, and mantle wedge $V p / V s$. Two sets of signals dominate the receiver function data here: a Moho conversion and a signal from the dipping top of the subducting slab.

[52] Crustal thickness varies by from 27 to $45 \mathrm{~km}$ with thickest crust offset somewhat south of the highest topography of the Alaska Range. Thin crust (30 km thick) is found north of the Hines Creek fault, likely indicating that density differences associated with terrane boundaries are important in compensating topography. The average crustal $\mathrm{Vp} / \mathrm{Vs}$ of 1.78 corresponds to that of mafic rocks, as expected for the accreted terranes making up much of southern Alaska. A belt of high $V p / V s(1.95 \pm 0.04)$ lies near the Hines Creek Fault, site of closure of a Cretaceous ocean basin, and may reflect relict structure associated with that fossil subduction.

[53] Inversion for the slab interfaces recovers the depths and thicknesses of the LVZ as estimated by other methods, and confirms that a thick, slow layer persists to $130 \mathrm{~km}$ depth. This layer is likely a subducting exotic terrane that is $15-20 \mathrm{~km}$ thick and perhaps represents a downdip extent of the Yakutat terrane crust. The $V p / V s$ of $1.79 \pm 0.06$ in the southern part of the mantle wedge, where the subducting plate is $<80 \mathrm{~km}$ deep, may reflect slight serpentinization of the shallowest part of the wedge but does not require any. This is the same part of the mantle wedge where low temperatures and high magnetization have been indicated previously.

[54] Farther north, where the wedge has been inferred to be hot, we observe unusually low $V p / V_{S}$ values $(1.6-1.7)$, confirmed by local traveltime tomography. Such low $V p / V S$ values are difficult to reconcile with any major rock- 
forming mineral common to mafic or ultramafic rocks, although highly depleted peridotites or orthopyroxenites lie close to this range. Abundant quartz may be required to explain the observed $V p / V s$, indicating that past subduction has significantly modified mantle material here.

[55] Acknowledgments. We thank the many collaborators who made the BEAAR data set possible, in particular L. Veenstra, J. Stachnik, A. Ferris and R. Hansen, and the staff of the IRIS-PASSCAL Instrument Center who enabled this project. The discussion benefited from reviews by T. Brocher and an anonymous reviewer and from fruitful exchanges and early access to results with D. Eberhart-Phillips and R. Blakely. We thank A. Frederiksen for making his modeling code available to us. This work supported by NSF grants EAR-9996451 and EAR-0215577 to G.A. S.R. was partly funded by a Kerr-McGee career development chair at MIT. Some figures made using GMT [Wessel and Smith, 1991].

\section{References}

Abers, G. A., P. E. van Keken, E. A. Kneller, A. Ferris, and J. C. Stachnik (2006), The thermal structure of subduction zones constrained by seismic imaging: Implications for slab dehydration and wedge flow, Earth Planet. Sci. Lett., 241, 387-397.

Ai, Y., D. Zhao, X. Gao, and W. Xu (2005), The crust and upper mantle discontinuity structure beneath Alaska inferred from receiver functions, Phys. Earth Planet. Inter., 150, 339-350.

Akaogi, M., H. Yusa, K. Shiraishi, and T. Suzuki (1995), Thermodynamic properties of alpha quartz, coesite and stishovite and equilibrium phaserelations at high-pressures and high-temperatures, J. Geophys. Res., 100, $22,337-22,347$

Angel, R. J., and J. M. Jackson (2002), Elasticity and equation of state of orthoenstatite, $\mathrm{MgSiO}_{3}$, Am. Mineral., 87, 558-561.

Beaudoin, B. C., G. S. Fuis, W. D. Mooney, W. J. Nokleberg, and N. I Christensen (1992), Thin, low-velocity crust beneath the southern YukonTanana Terrane, east central Alaska; results from Trans-Alaska Crustal Transect refraction/wide-angle reflection data, J. Geophys. Res., 97, $1921-1942$.

Bebout, G. E. (1996), Volatile transfer and recycling at convergent margins: Mass-balance and insights from high-P/T metamorphic rocks, in Subduction Top to Bottom, Geophys. Monogr. Ser, vol. 97, edited by G. E. Bebout et al., pp. 179-193, AGU, Washington, D. C.

Blakely, R. J., T. M. Brocher, and R. E. Wells (2005), Subduction-zone magnetic anomalies and implications for hydrated forearc mantle, Geology, 33, 445-448.

Bostock, M. G., and S. Rondenay (1999), Migration of scattered teleseismic body waves, Geophys. J. Int., 137, 732-746.

Bostock, M. G., S. Rondenay, and J. Shragge (2001), Multiparameter twodimensional inversion of scattered teleseismic body waves: 1 . Theory for oblique incidence, J. Geophys. Res., 106, 30,771-30,782.

Bostock, M. G., R. D. Hyndman, S. Rondenay, and S. M. Peacock (2002), An inverted continental Moho and serpentinization of the forearc mantle, Nature, 417, 536-538.

Brocher, T. M. (2005), Empirical relations between elastic wavespeeds and density in the Earth's crust, Bull. Seismol. Soc. Am., 95, 2081-2092.

Brocher, T. M., G. S. Fuis, M. A. Fisher, G. Plafker, M. J. Moses, J. J. Taber, and N. I. Christensen (1994), Mapping the megathrust beneath the northern Gulf of Alaska using wide-angle seismic data, J. Geophys. Res., 99, 11,663-11,685.

Brocher, T. M., G. S. Fuis, W. J. Lutter, N. I. Christensen, and N. A. Ratchkovski (2004), Seismic velocity models for the Denali fault zone along the Richardson Highway, Alaska, Bull. Seismol. Soc. Am., 94, S85-S106.

Chevrot, S., and R. D. van der Hilst (2000), The Poisson's ratio of the Australian crust: Geological and geophysical implications, Earth Planet. Sci. Lett., 183, 121-132.

Christensen, D. H., G. A. Abers, and T. McNight (2003), Mantle anisotropy beneath the Alaska Range inferred from S-wave splitting observations: Results from BEAAR, Eos Trans. AGU, 84, Fall Meet. Suppl., Abstract S31C-0782.

Christensen, N. I. (1996), Poisson's ratio and crustal seismology, J. Geophys. Res., 101, 3139-3157.

Cook, F. A. (1986), Continental evolution by lithospheric shingling, in Reflection Seismology: The Continental Crust, Geodyn. Ser., vol. 14, edited by M. Barazangi and L. Brown, pp. 13-19, AGU, Washington, D. C.

Diebold, J. B. (1987), Three-dimensional travel time equation for dipping layers, Geophysics, 52, 1492-1500.

Dziewonski, A. M., and D. L. Anderson (1981), Preliminary reference Earth model, Phys. Earth Planet. Inter, 25, 297-356.
Eberhart-Phillips, D., D. H. Christensen, T. M. Brocher, R. Hansen, N. A. Ruppert, P. J. Haueussler, and G. A. Abers (2006), Imaging the transition from Aleutian subduction to Yakutat collision in central Alaska, with local earthquakes and active source data, J. Geophys. Res., doi:10.1029/2005JB004240, in press.

Ernst, W. G., and J. G. Liou (1999), Overview of UHP metamorphism and tectonics in well-studied collisional orogens, Int. Geol. Rev., 41, 477493.

Ferris, A., G. A. Abers, D. H. Christensen, and E. Veenstra (2003), High resolution image of the subducted Pacific plate beneath central Alaska, $50-150 \mathrm{~km}$ depth, Earth Planet. Sci. Lett., 214, 575-588.

Fletcher, H. J., and J. T. Freymueller (1999), New GPS constraints on the motion of the Yakutat Block, Geophys. Res. Lett., 26, 3029-3032.

Frederiksen, A. W., and M. G. Bostock (2000), Modelling teleseismic waves in dipping anisotropic structures, Geophys. J. Int., 141, 401-412.

Fuis, G. S., E. L. Ambos, W. D. Mooney, N. I. Christensen, and E. Geist (1991), Crustal structure of accreted terranes in southern Alaska, Chugach Mountains and Copper River basin, from seismic refraction results, J. Geophys. Res., 96, 4187-4227.

Gerya, T. V., and D. A. Yuen (2003), Rayleigh-Taylor instabilities from hydration and melting propel 'cold plumes' at subduction zones, Earth Planet. Sci. Lett., 212, 47-62.

Green, D. H., and T. J. Falloon (1998), Pyrolite: A Ringwood concept and its current expression, in The Earth's Mantle, edited by I. Jackson, pp. 311-378, Cambridge Univ. Press, New York.

Hacker, B. R., and G. A. Abers (2004), Subduction factory: 3. An Excel worksheet and macro for calculating the densities, seismic wave speeds, and $\mathrm{H}_{2} \mathrm{O}$ contents of minerals and rocks at pressure and temperature, Geochem. Geophys. Geosyst., 5, Q01005, doi:10.1029/2003GC000614.

Hacker, B. R., G. A. Abers, and S. M. Peacock (2003a), Subduction factory: 1 . Theoretical mineralogy, densities, seismic wave speeds, and $\mathrm{H}_{2} \mathrm{O}$ contents, J. Geophys. Res., 108(B1), 2029, doi:10.1029/2001JB001127.

Hacker, B. R., S. M. Peacock, G. A. Abers, and S. D. Holloway (2003b), Subduction factory: 2 . Are intermediate-depth earthquakes in subducting slabs linked to metamorphic dehydration reactions?, J. Geophys. Res., 108(B1), 2030, doi:10.1029/2001JB001129.

Hyndman, R. D., and S. M. Peacock (2003), Serpentinization of the forearc mantle, Earth Planet. Sci. Lett., 212, 417-432.

Karato, S. (1993), Importance of anelasticity in the interpretation of seismic tomography, Geophys. Res. Lett., 20, 1623-1626.

Kennett, B. L. N. (1991), Removal of free surface interactions from threecomponent seismograms, Geophys. J. Int., 104, 153-163.

Kennett, B. L. N., and E. R. Engdahl (1991), Travel times for global earthquake location and phase identification, Geophys. J. Int., 105, 429-465.

Koper, K. D., D. A. Wiens, L. Dorman, J. Hildebrand, and S. Webb (1999), Constraints on the origin of slab and mantle wedge anomalies in Tonga from the ratio of S to P velocities, J. Geophys. Res., 104, 15,089-15,104.

Matsuzawa, T., N. Umino, A. Hasegawa, and A. Takagi (1986), Upper mantle velocity structure estimated from PS-converted wave beneath the north-eastern Japan Arc, Geophys. J. R. Astron. Soc., 86, 767-787.

McNamara, D. E., and M. E. Pasyanos (2002), Seismological evidence for a sub-volcanic arc mantle wedge beneath the Denali volcanic gap, Alaska, Geophys. Res. Lett., 29(16), 1814, doi:10.1029/2001GL014088.

Molnar, P., and D. Gray (1979), Subduction of continental lithosphere: Some constraints and uncertainties, Geology, 7, 58-62.

Page, R. A., C. D. Stephens, and J. C. Lahr (1989), Seismicity of the Wrangell and Aleutian Wadati-Benioff zones and the North America plate along the Trans-Alaska Crustal Transect, Chugach Mountains and Copper River basin, southern Alaska, J. Geophys. Res., 94, 16,05916,082 .

Pavlis, T. L., C. Picornell, L. Serpa, R. L. Bruhn, and G. Plafker (2004), Tectonic processes during oblique collision: Insights from the St. Elias orogen, northern North American Cordillera, Tectonics, 23, TC3001, doi:10.1029/2003TC001557

Plafker, G., W. J. Nokleberg, and J. S. Lull (1989), Bedrock geology and tectonic evolution of the Wrangellia, Peninsular, and Chugach terranes along the Trans-Alaska Crustal Transect in the Chugach Mountains and southern Copper River basin, Alaska, J. Geophys. Res., 94, 4255-4296.

Plafker, G., J. C. Moore, and G. R. Winkler (1994), Geology of the southern Alaska margin, in The Geology of North America, vol. G-1, The Geology of Alaska, edited by G. Plafker and H. C. Berg, pp. 389-449, Geol. Soc. of Am., Boulder, Colo.

Ratchkovski, N., and R. Hansen (2002), New evidence for segmentation of the Alaska subduction zone, Bull. Seismol. Soc. Am., 92, 1754-1765.

Ridgway, K. D., J. M. Trop, W. J. Nokleberg, C. M. Davidson, and K. R. Eastham (2002), Mesozoic and Cenozoic tectonics of the eastern and central Alaska Range: Progressive basin development and deformation in a suture zone, Geol. Soc. Am. Bull., 114, 1480-1504.

Roecker, S. W. (1993), Tomography in zones of collision: Practical considerations and examples, in Seismic Tomography Theory and Practice, 
edited by H. M. Iyer and K. Hirahara, pp. 534-611, CRC Press, Boca Raton, Fla.

Rondenay, S., G. A. Abers, and A. Ferris (2004), A new, high-resolution seismic profile of the central-Alaskan subduction zone, Eos Trans. AGU, 85(17), Jt. Assem. Suppl., Abstract U54A-05.

Rondenay, S., M. G. Bostock, and K. M. Fischer (2005), Multichannel inversion of scattered teleseismic body waves: Practical considerations and applicability, in Seismic Earth: Array Analysis of Broadband Seismograms, Geophys. Monogr. Ser., vol. 157, edited by A. Levander and G. Nolet, pp. 187-204, AGU, Washington, D. C.

Rossi, G. (2004), Measuring the mantle wedge Poisson's ratio and slab depth: Central Alaska, M.A. thesis, 121 pp, Boston Univ., Boston, Mass.

Saleeby, J. B. (1983), Accretionary tectonics of the North American Cordillera, Annu. Rev. Earth Planet. Sci., 15, 45-73.

Saltzer, R. L., E. Stutzmann, and R. D. van der Hilst (2004), Poisson's ratio in the lower mantle beneath Alaska: Evidence for compositional heterogeneity, J. Geophys. Res., 109, B06301, doi:10.1029/2003JB002712

Schmidt, M. W., and S. Poli (1998), Experimentally based water budgets for dehydrating slabs and consequences for arc magma generation, Earth Planet. Sci. Lett., 163, 361-379.

Stachnik, J. C. (2002), Seismic attenuation in central Alaska, M.A. thesis, 122 pp, Boston Univ., Boston, Mass.

Stachnik, J. C., G. A. Abers, and D. Christensen (2004), Seismic attenuation and mantle wedge temperatures in the Alaska subduction zone, J. Geophys. Res., 109, B10304, doi:10.1029/2004JB003018.

Stanley, W. D., V. F. Labson, W. J. Nokleberg, J. B. Csejtey, and M. A. Fisher (1990), The Denali fault system and Alaska Range of Alaska: Evidence for underplated Mesozoic flysch from magnetotelluric surveys, Geol. Soc. Am. Bull., 102, 160-173.

Takei, Y. (2002), Effect of pore geometry on $V_{P} / V d$ : From equilibrium geometry to crack, J. Geophys. Res., 107(B2), 2043, doi:10.1029/ 2001JB000522.

Thurber, C., S. Roecker, K. Roberts, M. Gold, L. Powell, and K. Rittger (2003), Earthquake locations and three-dimensional fault zone structure along the creeping section of the San Andreas fault near Parkfield, CA: Preparing for SAFOD, Geophys. Res. Lett., 30(3), 1112, doi:10.1029 2002GL016004

Ulmer, P., and V. Trommsdorf (1995), Serpentine stability to mantle depths and subduction-related magmatism, Science, 268, 858-861.
VanDecar, J. C., and R. S. Crosson (1990), Determination of teleseismic relative phase arrival times using multi-channel cross-correlation and least squares, Bull. Seismol. Soc. Am., 80, 150-159.

Veenstra, E., D. H. Christensen, G. A. Abers, and A. Ferris (2006), Crustal thickness variation in south central Alaska: Results from the Broadband Experiment Across the Alaska Range, Geology, 34, 781-784.

Wagner, L. S., S. Beck, and G. Zandt (2005), Upper mantle structure in the south central Chilean subduction zone $\left(30^{\circ}\right.$ to $\left.36^{\circ} \mathrm{S}\right)$, J. Geophys. Res., 110, B01308, doi:10.1029/2004JB003238.

Wessel, P., and W. H. F. Smith (1991), Free software helps map and display data, Eos Trans. $A G U, 72,441,445-446$.

Zandt, G., and C. J. Ammon (1995), Continental crust composition constrained by measurements of crustal Poisson's ratio, Nature, 374, 152 - 154 .

Zhang, H., C. Thurber, D. Shelly, S. Ide, G. Beroza, and A. Hasegawa (2004), High-resolution subducting-slab structure beneath northern Honshu, Japan, revealed by double-difference tomography, Geology, 32, 361-364.

Zhao, D., D. H. Christensen, and H. Pulpan (1995), Tomographic imaging of the Alaska subduction zone, J. Geophys. Res., 100, 6487-6504.

Zhao, D., H. Kanamori, H. Negishi, and D. A. Wiens (1996), Tomography of the source area of the 1995 Kobe earthquake: Evidence for fluids at the hypocenter?, Science, 274, 1891-1894.

Zheng, Y., and T. Lay (2006), Low $V_{p} / V_{s}$ ratios in the crust and upper mantle beneath the Sea of Okhotsk inferred from teleseismic $p_{M} P, s_{M} P$, and $s_{M} S$ underside reflections from the Moho, J. Geophys. Res., 111, B01305, doi:10.1029/2005JB003724.

Zhu, L., and H. Kanamori (2000), Moho depth variation in southern California from teleseismic receiver functions, J. Geophys. Res., 105, 29692980.

G. A. Abers and G. Rossi, Department of Earth Sciences, Boston University, 685 Commonwealth Avenue, Boston, MA 02215, USA (abers@bu.edu)

D. H. Christensen, Geophysical Institute, University of Alaska Fairbanks, 903 Koyukuk Drive,P.O. Box 757320, Fairbanks, AK 99775-7320, USA.

S. Rondenay, Department of Earth, Atmospheric and Planetary Sciences, Massachusetts Institute of Technology, 77 Massachusetts Avenue, 54-512, Cambridge, MA 02139, USA. 